\title{
Clinical Pharmacokinetics and Pharmacodynamics of the Epidermal Growth Factor Receptor Inhibitor Panitumumab in the Treatment of Colorectal Cancer
}

\author{
Sander Ketzer ${ }^{1} \cdot$ Kirsten Schimmel $^{1} \cdot$ Miriam Koopman $^{2} \cdot$ Henk-Jan Guchelaar $^{1}$
}

Published online: 29 August 2017

(c) The Author(s) 2017. This article is an open access publication

\begin{abstract}
Despite progress in the treatment of metastatic colorectal cancer (mCRC) in the last 15 years, it is still a condition with a relatively low 5-year survival rate. Panitumumab, a fully human monoclonal antibody directed against the epidermal growth factor receptor (EGFR), is able to prolong survival in patients with mCRC. Panitumumab is used in different lines of therapy in combination with chemotherapy, and as monotherapy for the treatment of wild-type (WT) RAS mCRC. It is administered as an intravenous infusion of $6 \mathrm{mg} / \mathrm{kg}$ every 2 weeks and has a $t_{1 / 2}$ of approximately 7.5 days. Elimination takes place via two different mechanisms, and immunogenicity rates are low. Only RAS mutations have been confirmed as a negative predictor of efficacy with anti-EGFR antibodies. Panitumumab is generally well tolerated and has a manageable toxicity profile, despite a very high prevalence of dermatologic side effects. This article presents an overview of the clinical pharmacokinetics and pharmacodynamics of panitumumab, including a description of the studies that led to its approval in the different lines of therapy of mCRC.
\end{abstract}

Henk-Jan Guchelaar

h.j.guchelaar@lumc.nl

1 Department of Clinical Pharmacy and Toxicology, Leiden University Medical Center, P.O. Box 9600, 2300 RC Leiden, The Netherlands

2 Department of Medical Oncology, University Medical Center Utrecht, Utrecht, The Netherlands

\section{Key Points}

Panitumumab, a fully human monoclonal antibody directed against the epidermal growth factor receptor, is used in all lines of therapy in the treatment of metastatic colorectal cancer. Its place in therapy relative to other biological agents is still unclear.

Pantitumumab is administered as an intravenous infusion of $6 \mathrm{mg} / \mathrm{kg}$ over $60 \mathrm{~min}$, and it has dual clearance mechanisms.

Panitumumab treatment is only indicated for patients with wild-type $R A S$ tumors. Much research is directed at identifying other biomarkers with the potential of predicting efficacy benefits.

\section{Introduction}

Colorectal cancer (CRC) is a common form of cancer and it is estimated that there are 95,270 new cases of colon cancer and 39,220 new cases of rectum cancer annually in the US [1]. In Europe and Australia, the incidence rates are even higher [2]. With 49,190 deaths per year in the US, CRC is the third most frequent ( $8 \%$ of all cancer cases) and third most lethal form of cancer [1].

Surgical resection is an essential part of therapy for localized CRC with curative intention. In metastatic colorectal cancer (mCRC) without the option of resection of disease, systemic chemotherapy is indicated as palliative 
treatment with the aim of prolonging survival, improving quality of life, and reducing and controlling symptoms.

As first-line therapy, a cytotoxic doublet; 5-fluorouracil with folinic acid plus oxaliplatin (FOLFOX), capecitabine plus oxaliplatin (CAPOX) or 5-fluorouracil with folinic acid plus irinotecan (FOLFIRI), or the triplet consisting of 5-fluorouracil with folinic acid, oxaliplatin and irinotecan (FOLFOXIRI), could be combined with bevacizumab. In patients unfit for these combination therapies, or in patients who are asymptomatic or have low disease activity, a fluoropyrimidine plus bevacizumab is the preferred choice of treatment. Another option is combining an epidermal growth factor receptor (EGFR) antibody with FOLFOX or FOLFIRI. To date, there is no unequivocal evidence for the superiority of one of these options in first-line treatment of patients with $R A S$ wild-type (WT) mCRC, with the exception of right-sided tumors, because recent studies show that right-sided RAS WT patients do not benefit from anti-EGFR therapy [3-5]. In second-line treatment, aflibercept or ramucirumab could also be considered, while regorafenib and trifluridine/tipiracil are available for thirdline treatment of $\mathrm{mCRC}$.

The EGFR antibodies target the EGFR, also known as ErbB-1 or HER1. EGFR is a receptor on the cell surface where members of the epidermal growth factor (EGF) family of extracellular protein ligands can bind. Various ligands can activate these receptors, including EGF, transforming growth factor (TGF)- $\alpha$, heparin-binding EGF (HB-EGF), amphiregulin, betacellulin, epigen and epiregulin [6]. Upon activation, EGFR undergoes transition from an inactive monomeric form to an active homodimer or heterodimer (with another member of the ErbB family). EGFR dimerization stimulates its catalytic intracellular protein tyrosine kinase activity, and, as a result, autophosphorylation of several tyrosine residues occurs and elicits downstream activation and signaling by several other proteins that associate with the phosphorylated tyrosines. These downstream signaling proteins initiate several signal transduction cascades, including the RAS/RAF/ MAPK, P13K/AKT, and STAT pathways, leading to increased cell proliferation, increased angiogenesis, migration, metastasis, and increased cell survival by blocking apoptosis (Fig. 1) [6-9].

There are two classes of drugs in clinical use that target the EGFR. The monoclonal antibodies (mAbs) bind on the extracellular site of the EGFR, thereby blocking the ligandbinding region and preventing activation, whereas the tyrosine kinase inhibitors compete intracellularly with adenosine triphosphate (ATP) for the binding spot and inhibit autophosphorylation [8].

Cetuximab was the first EGFR-targeting mAb available for the treatment of $\mathrm{mCRC}$, with panitumumab following a few years later. Panitumumab is a fully human mAb of the immunoglobulin (Ig) G2 subtype specific to EGFR.

In September 2006, the US FDA authorized the introduction of panitumumab into the US market. This drug is indicated as first-line therapy in combination with FOLFOX, or in third and subsequent lines of therapy as monotherapy for the treatment of chemofractory mCRC after disease progression on or following irinotecan-, fluoropyrimidine- and oxaliplatin-containing chemotherapy regimens. Panitumumab is contraindicated in patients with an $R A S$-mutated $\mathrm{mCRC}$ or if the $R A S \mathrm{mCRC}$ status is unknown. Marketing authorization was approved by the European Medicines Agency (EMA) in Europe in December 2007. The EMA registered panitumumab for the treatment of adults with WT RAS mCRC as first-line treatment in combination with FOLFOX or FOLFIRI, as second-line therapy in combination with FOLFIRI for patients who have received first-line fluoropyrimidinebased chemotherapy (excluding irinotecan), and as a single agent after the failure of chemotherapy regimens containing irinotecan, fluoropyrimidine, and oxaliplatin.

In this paper, we present an overview of the pharmacokinetics (PK) and pharmacodynamics (PD) of panitumumab, and provide an up-to-date overview of the current position of panitumumab in the treatment of mCRC. In recent years, results from pivotal studies have been published, and research on biomarkers has advanced progressively, justifying the need for this review.

\section{Pharmacokinetics}

The recommended dose of panitumumab is $6 \mathrm{mg} / \mathrm{kg}$ of bodyweight administered once every 2 weeks [10, 11].

A phase I dose-finding study found no difference in panitumumab trough concentrations for this dose regimen compared with two other schedules: $2.5 \mathrm{mg} / \mathrm{kg}$ weekly and $9 \mathrm{mg} / \mathrm{kg}$ every 3 weeks [12]. Steady-state was reached after 6 weeks for all cohorts, and safety profiles were also similar. The maximum tolerated dose was not reached.

The three dose regimens were also examined in a phase I trial in Japanese patients [13], and a similar PK and safety profile was found in both Japanese and non-Japanese patients.

The recommended time of infusion is $60 \mathrm{~min}[10,11]$, although an infusion time of $30 \mathrm{~min}$ could be recommended if the first dose administered over $60 \mathrm{~min}$ was well tolerated. A phase I study compared these infusion durations and found maximum concentration $\left(C_{\max }\right)$ values were the same for infusions of $6 \mathrm{mg} / \mathrm{kg}$ every 2 weeks administered over 60 and $30 \mathrm{~min}$ [14]. No differences in safety were noted for these two infusion durations. This can be explained because distribution, in particular the 
Fig. 1 EGFR signaling pathways. Upon binding of a ligand, EGFR undergoes transition from an inactive monomeric form $(A)$ to an active dimer or heterodimer. EGFR dimerization stimulates its catalytic intracellular protein tyrosine kinase activity $(B)$ and elicits downstream activation and signaling. EGFR epidermal growth factor receptor, $P$ phosphorylated, $P I 3 K$ phosphatase and tensin homolog, mTOR mechanistic target of rapamycin, $J A K$ janus kinase, STAT signal transducer and activator of transcription, $S H C$ src homology 2 domain containing, GRB2 growth factor receptor-bound protein $2, \operatorname{SOS}$ son of sevenless, MEK MAPK/ ERK kinase, MAPK mitogenactivated protein kinase

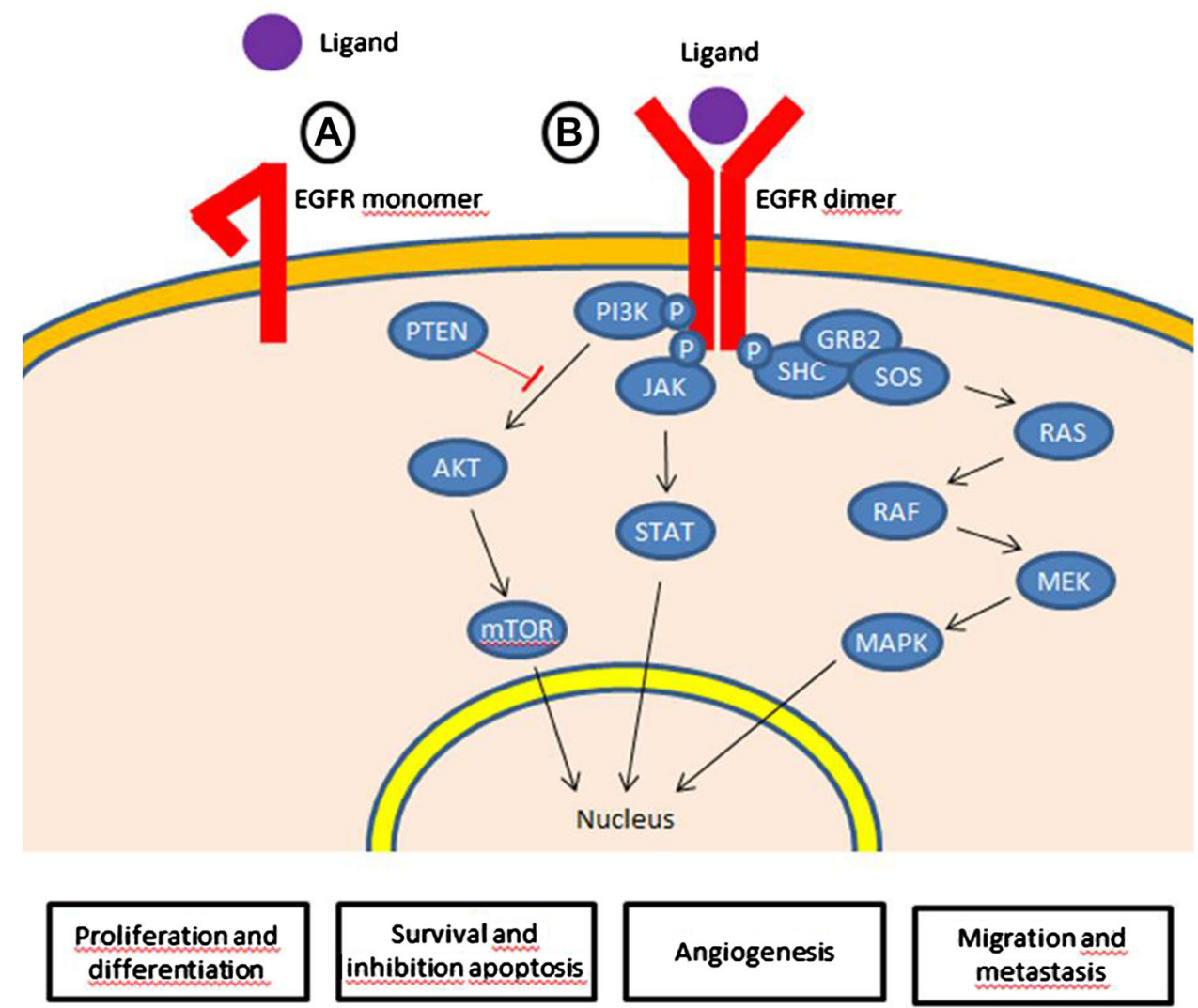

elimination phase, takes significantly more time than the length of the infusion. For doses exceeding $1000 \mathrm{mg}$, an infusion time of $90 \mathrm{~min}$ is advised [10, 11].

The PK of panitumumab is best described with a model that includes both linear and nonlinear clearance mechanisms [15]. Concentrations of panitumumab increase nonlinearly with the administered dose at doses of $0.75-2 \mathrm{mg} / \mathrm{kg}$, but at doses $>2 \mathrm{mg} / \mathrm{kg}$ the area under the concentration-time curve (AUC) increases proportionally with the dose $[10,11,13,15]$. Clearance decreased with an increase in dose, due to the dual elimination mechanisms, as is also seen with other mAbs that target membrane-bound antigens. The binding of panitumumab to EGFR results in nonlinear elimination because the mAb target complex is internalized and degraded. This process is known as target-mediated drug disposition (TMDD). Since the available number of EGF receptors is limited, this is a saturable and dose-dependent process of elimination. Clearance depends on the plasma concentration, and, as with higher concentrations, clearance via TMDD decreases. Additionally, the number of receptors affects the clearance of panitumumab. This mechanism plays an important role in the clearance of panitumumab from the systemic circulation. Nonspecific linear clearance takes place via the reticuloendothelial system. With doses of $2.5 \mathrm{mg} / \mathrm{kg}$, full receptor occupation was achieved, based on a 100\% skin rash incidence at this dose level $[15,16]$.

A PK population model of panitumumab, based on data from 1200 patients with solid tumors from 14 different studies, confirmed that disposition is best described using a two-compartment model with parallel linear and nonlinear clearance mechanisms [17]. For a typical male patient ( 60 years of age, $80 \mathrm{~kg}$ ) with CRC, this model provides the following PK parameters: a linear clearance of $0.273 \mathrm{~L} / 24 \mathrm{~h}$, a maximum nonlinear clearance of $28.4 \mathrm{~L} / 24 \mathrm{~h}$, a central and peripheral volume of distribution of 3.95 and $2.59 \mathrm{~L}$, respectively, and a Michaelis-Menten constant of $0.426 \mu \mathrm{g} / \mathrm{mL}$. The maximum nonlinear clearance is much higher than that of cetuximab $(1.42 \mathrm{~L} / 24 \mathrm{~h})$, which could be the result of the higher affinity of panitumumab for EGFR [18]. The small volume of distribution is primarily the consequence of the large molecular weight of panitumumab. Its volume of distribution is predominantly restricted to vascular and interstitial spaces. Furthermore, the total volume of distribution is less than half of the total extracellular water volume because extracellular matrix proteins and other constituents prevent panitumumab from distributing into the entire compartment. The Michaelis-Menten constant is the panitumumab concentration at which the elimination rate is half its 
maximum $\left(V_{\max }\right)$. At doses $>2 \mathrm{mg} / \mathrm{kg}$, when the AUC increases proportionally with the dose, it can be assumed that $V_{\max }$ is reached and EGFR is assumed to be saturated at these doses. No clinical benefit is to be expected at doses higher than the registered dose of $6 \mathrm{mg} / \mathrm{kg}$ of bodyweight.

The manufacturer reports the following data: at steady state, the mean peak concentration was $213 \mu \mathrm{g} / \mathrm{mL}$ [standard deviation (SD) 59] and the mean trough level was $39 \mu \mathrm{g} / \mathrm{mL}$ (SD 14) [10, 11]. The corresponding AUC was, on average, $1306 \mu \mathrm{g} *$ day $/ \mathrm{mL}$ (SD 374) and the mean clearance was $4.9 \mathrm{~mL} / \mathrm{kg} /$ day (SD 1.4). The elimination half-life $\left(t_{1 / 2}\right)$ varied from 3.6 to 10.9 days (mean 7.5 days). This long $t_{1 / 2}$ is the result of panitumumab being a fully human antibody with the ability to bind to the neonatal $\mathrm{Fc}$ receptor $(\mathrm{FcRn})$ with the $\mathrm{Fc}$ domain. Binding of panitumumab within endomes to the FcRn protects it from lysosomal degradation as only the free fraction is catabolized in lysosomes. In this way, a large portion of panitumumab is recycled back into circulation. Antibodies with more murine material have less binding capacity to the FcRn, and, moreover, a greater number of anti-drug antibodies are formed.

Panitumumab exposure was found to be most influenced by body weight and, to a much smaller extent, by age, sex and cancer type [17]. PK were unaffected by race, concomitant chemotherapy, and baseline tumor EGFR expression. A population $\mathrm{PK}$ analysis reported by the manufacturer confirms these findings [10, 11]. Results suggest that sex, age (21-88 years), race, renal and hepatic function, chemotherapeutic agents, and EGFR membrane staining intensity in tumor cells did not significantly alter the PK of panitumumab. These data substantiate that dosing based on body weight is the best way to achieve similar exposure in patients.

No PK interactions of panitumumab with other drugs have been reported to date due to its endogenous elimination not being mediated by transporters, such as P-glycoprotein, and enzymes, such as cytochrome P450, and/or by renal and biliary excretion. Second, changes in TMDD due to down- or upregulation of EGFR by other drugs are not to be expected.

The possible influence of coadministration of panitumumab with irinotecan has been the subject of study. Nineteen patients received irinotecan $\left(180 \mathrm{mg} / \mathrm{m}^{2}\right.$ intravenously) and panitumumab (6 mg/kg intravenously) [19]. In cycle 1 , panitumumab was administered 3 days after irinotecan administration, while in cycle 2 , panitumumab administration was directly followed by the administration of irinotecan. No influence of panitumumab coadministration on irinotecan PK was found.

\section{Pharmacodynamics}

Panitumumab was generated using XenoMouse ${ }^{\mathrm{TM}}$ technology; human immunoglobulin genes were introduced in genetically engineered mice which had no functional mouse immunoglobulin expression. For production of panitumumab, genetically engineered Chinese hamster ovary cells are used. Panitumumab, an IgG2 mAb, was shown to bind EGFR with high affinity; $K_{\mathrm{D}}=5 \times 10^{-11} \mathrm{M}$ [20]. The affinity of panitumumab for EGFR is higher than that of cetuximab, with reported $K_{\mathrm{D}}$ values of $15-39 \times 10^{-11} \mathrm{M}[21,22]$. This strong affinity for EGFR is the consequence of fast association rates combined with slow dissociation rates [23]. Panitumumab can bind bivalenty to two EGFRs. By binding to the extracellular domain of this receptor, panitumumab does not activate the receptor but prevents binding of endogenous ligands [20, 23]. As a result, these ligands cannot activate the receptor and subsequent dimerization and autophosphorylation will not take place. When panitumumab is bound to EGFR, the receptor is incapable of dimerization [23], which results in decreased proliferation, decreased angiogenesis, and apoptosis of tumor cells. Furthermore, the binding of panitumumab results in internalization of EGFR in tumor cells [20].

Antibody-dependent cell-mediated cytotoxicity (ADCC) and complement-dependent cytotoxicity (CDC) are often part of the mechanism of action of therapeutic mAb's. ADCC involves binding of the antibody coupled to the target cell to an $\mathrm{Fc} \gamma$ receptor on an effector cell of the immune system, mainly natural killer cells. The target cell is then lysed by the effector cell. With CDC, the antibody binds to complement components, which can have an antitumor effect via membrane attack complexes. As panitumumab is a fully human antibody of the IgG2 isotype, ADCC and CDC were not expected to play a major role because the ability of $\operatorname{IgG} 2$ to bind $\mathrm{Fc} \gamma$ receptors and complement components is very limited. The IgG2 subtype has the least potential for induction of ADCC of the four $\mathrm{IgG}$ subtypes, and $\mathrm{IgG} 1$ and $\mathrm{IgG} 3$ are much stronger inducers of $\mathrm{CDC}$ than IgG2. Almost all therapeutic antibodies in clinical use are of the IgG1 isotype because this isotype is known to be very effective in triggering ADCC and CDC.

In squamous cell head and neck carcinomas, in vitro panitumumab was able to provoke ADCC in concentrations similar to those found in patients [24]. Panitumumab was also shown to be effective in recruiting ADCC by myeloid effector cell-mediated ADCC, but not in recruiting ADCC by natural killer cells [25]. The contribution of ADCC to the efficacy of panitumumab is unclear, which is in contrast 
with cetuximab, an IgG1 mAb, where ADCC was demonstrated to be part of its mechanism of action.

\subsection{Immunogenicity}

Since panitumumab is a fully human mAb, immunogenicity is expected to be very low; however, panitumumab could still be recognized as nonself by the human immune system because of unique sequences in the DNA structure, e.g. in the complementarity-determining regions. The development of anti-panitumumab antibodies could potentially lead to altered PK and efficacy and a different safety profile. To detect anti-panitumumab antibodies, two different screening assays have been used-an enzymelinked immunosorbent assay (ELISA) and a biosensor immunoassay (BIAcore assay). The biosensor immunoassay detects both low- and high-affinity antibodies, whereas ELISA detects mainly high-affinity antibodies. A biological assay can be used to identify if these antibodies have neutralizing capacities.

With regard to patients treated with panitumumab monotherapy, the product information states that the incidence of binding antibodies was $<1 \%$ as detected by ELISA, and 3.2\% (US) to 3.8\% (Europe) as detected by the BIAcore assay (excluding predose and transient positive patients); neutralizing antibodies were seen in $<1 \%$ of cases $[10,11]$. Lofgren et al. reported comparable results [26]. Overall, $0.3 \%$ (2 of 612) of patients treated with panitumumab developed nontransient anti-panitumumab antibodies detected with ELISA, one of which proved to be neutralizing antibodies. With the BIAcore assay, 4.1\% (25 of 604) of patients treated with panitumumab were found to have developed nontransient anti-panitumumab antibodies; $1.3 \%$ (8 of 604) of this population tested positive for neutralizing antibodies.

No relationship between the presence of anti-panitumumab antibodies and PK, efficacy, or safety has been observed [10,11, 17].

In combination with chemotherapy, the incidences of binding antibodies are also low. In the trial by Weeraratne et al., $1.8 \%$ of 1124 patients developed binding antibodies and $0.2 \%$ developed neutralizing antibodies against panitumumab when combined with oxaliplatin or irinotecan [27]. The manufacturer reports even lower incidences of binding antibodies $(\leq 1 \%)$ in this specific population $[10,11]$; therefore, the emergence of immunogenicity is also infrequent in this population, and comparable with patients treated with monotherapy. KRAS status did not influence the development of antibodies [27]. Population PK analysis showed that PK were similar in patients who were both positive and negative for anti-panitumumab antibodies $[10,11]$. The safety profile did not appear to be altered in patients who developed antibodies.

\section{Efficacy}

Panitumumab has been approved for use in first-, secondand third-line treatment of mCRC. In this section, the available evidence that led to and supports the application of panitumumab in these lines of therapy is presented.

\subsection{First-Line Therapy}

The most important results of clinical studies that investigated panitumumab as part of first-line treatment are summarized in Table 1.

The PRIME study was the pivotal phase III trial where panitumumab was investigated as first-line therapy in mCRC. Overall, 1183 chemotherapy-naive patients were randomly assigned to panitumumab plus FOLFOX4 (arm A) or FOLFOX4 alone (arm B) [28]. KRAS status was determined as patients were included in the study, and the following outcomes only relate to the 656 patients with WT KRAS mutation status. The objective response rate (ORR) was higher in arm A (57 vs. $48 \%)$. Median progression-free survival (PFS) was 10.0 months in arm A and 8.6 months in arm B [hazard ratio (HR) $0.80,95 \%$ confidence interval (CI) $0.67-0.95, p=0.01$ [ [29], while median overall survival (OS) was also significantly longer in arm A compared with arm B, i.e. 23.8 months and 19.4 months, respectively (HR $0.83,95 \%$ CI $0.70-0.98, p=0.03$ ). In patients with baseline liver metastases only, the complete resection rate in arm A was $28 \%$ compared with $18 \%$ in arm B. Patients with mutant (MT) KRAS mCRC had significantly shorter PFS (9.2 vs. 7.3 months; HR 1.27, 95\% CI 1.04-1.55, $p=0.02$ ) and shorter OS if treated with panitumumab plus FOLFOX4 versus FOLFOX4 alone, which was ascribed to a PD interaction with oxaliplatin in MT KRAS subjects. A higher response rate (RR) and longer PFS and OS were seen in patients who developed grade $2-4$ skin toxicity versus patients with only grade $0-1$ skin toxicity. Despite the large number of grade 3 or higher skin toxicity, panitumumab had no negative effect on overall quality of life (assessed using the EuroQol 5-domain health state index and overall health) $[30,31]$. A quality-adjusted time without symptoms of disease or toxicity of treatment (Qtwist) was performed to provide an integrated measure of clinical benefit [32]. The quality-adjusted survival in arm A was significantly longer than in arm B, i.e. 20.5 and 18.2 months, respectively.

Another first-line phase III trial (PACCE) resulted in a negative recommendation for the addition of panitumumab $(6 \mathrm{mg} / \mathrm{kg}$ every 2 weeks) to bevacizumab $(10 \mathrm{mg} / \mathrm{kg}$ every 2 weeks) with chemotherapy [33]. In this randomized trial, patients received panitumumab plus bevacizumab and chemotherapy or only bevacizumab with chemotherapy. As 
Table 1 Efficacy data of first-line panitumumab trials

\begin{tabular}{|c|c|c|c|c|c|c|c|c|c|}
\hline Study & $\begin{array}{l}\text { KRAS } \\
\text { status }\end{array}$ & Treatment arm & $\begin{array}{l}\text { No. of } \\
\text { patients }\end{array}$ & $\begin{array}{l}\text { Median PFS } \\
\text { (months) }\end{array}$ & $\begin{array}{l}\text { HR } \\
(p \text { value })\end{array}$ & $\begin{array}{l}\text { Median OS } \\
\text { (months) }\end{array}$ & $\begin{array}{l}\text { HR } \\
(p \text { value })\end{array}$ & $\begin{array}{l}\text { ORR } \\
(\%)\end{array}$ & $\begin{array}{l}\text { OR } \\
(p \text { value })\end{array}$ \\
\hline \multirow{4}{*}{$\begin{array}{l}\text { PRIME } \\
\quad[28,29]\end{array}$} & \multirow[t]{2}{*}{ WT KRAS } & $\mathrm{P}+\mathrm{FOLFOX} 4$ & 325 & 10.0 & \multirow[t]{2}{*}{$0.80(0.01)$} & 23.8 & \multirow[t]{2}{*}{$0.83(0.03)$} & 57 & \multirow[t]{2}{*}{$1.47(0.02$} \\
\hline & & FOLFOX4 & 331 & 8.6 & & 19.4 & & 48 & \\
\hline & \multirow[t]{2}{*}{ MT KRAS } & $\mathrm{P}+\mathrm{FOLFOX} 4$ & 221 & 7.4 & \multirow[t]{2}{*}{$1.27(0.02)$} & 15.5 & \multirow[t]{2}{*}{$1.16(0.16)$} & 40 & \multirow[t]{2}{*}{$0.98(0.98$} \\
\hline & & FOLFOX4 & 219 & 9.2 & & 19.2 & & 41 & \\
\hline \multirow{2}{*}{$\begin{array}{l}\text { Berlin et al. } \\
\text { [35] }\end{array}$} & \multirow[t]{2}{*}{ Unselected } & $\mathrm{P}+\mathrm{IFL}$ & 19 & 5.6 & & 17 & & 47 & \\
\hline & & $\mathrm{P}+$ FOLFIRI & 24 & 10.9 & & 22.5 & & 33 & \\
\hline \multirow{2}{*}{$\begin{array}{l}\text { Köhne et al. } \\
\text { [36] }\end{array}$} & WT KRAS & $\mathrm{P}+$ FOLFIRI & 86 & 8.9 & \multirow[t]{2}{*}{0.5} & & & 56 & \multirow[t]{4}{*}{2.1} \\
\hline & MT KRAS & $\mathrm{P}+$ FOLFIRI & 59 & 7.2 & & & & 38 & \\
\hline \multirow[t]{2}{*}{ PEAK [37] } & WT $K R A S$ & $\mathrm{P}+\mathrm{mFOLFOX6}$ & 142 & 10.9 & \multirow{2}{*}{$\begin{array}{l}0.87 \\
\quad(0.353)\end{array}$} & 34.2 & \multirow[t]{2}{*}{$0.62(0.009)$} & 57.8 & \\
\hline & WT $K R A S$ & $\mathrm{~B}+\mathrm{mFOLFOX6}$ & 143 & 10.1 & & 24.3 & & 53.5 & \\
\hline
\end{tabular}

WT wild-type, $M T$ mutated, $P$ panitumumab, FOLFOX folinic acid/infusional 5-fluorouracil/oxaliplatin, IFL irinotecan/bolus 5-fluorouracil/folinic acid, FOLFIRI folinic acid/infusional 5-fluorouracil/irinotecan, $m F O L F O X$ modified FOLFOX, $B$ bevacizumab, $P F S$ progression-free survival, $H R$ hazard ratio, $O S$ overall survival, $O R R$ objective response rate, $O R$ odds ratio

chemotherapy regimens, two irinotecan-containing regimens and six different oxaliplatin-containing regimens were allowed. The study was prematurely closed when the interim efficacy analysis showed inferior PFS and greater toxicity in the panitumumab-containing treatment arm. The risk of death was higher in this arm (9 vs. 4\%) and patients experienced more grade 3-4 adverse events (87 vs. $72 \%$ ) $[33,34]$. The negative effect of panitumumab on median PFS and OS was seen in both irinotecan- and oxaliplatincontaining regimens, but because of the small sample size of the irinotecan-containing regimens, the $p$ value was not significant in this stratum. Furthermore, the outcomes were independent of KRAS mutation status. At the time the study was initiated, no efficacy and tolerability data were available from phase II studies that tested this combination of drugs.

Panitumumab as first-line therapy was also the subject of multiple phase II studies. In one of the first phase II trials, panitumumab $(2.5 \mathrm{mg} / \mathrm{kg}$ weekly $)$ was administered with IFL (irinotecan, leucovorin and bolus injections of 5-fluorouracil) or FOLFIRI [35]. The panitumumab plus IFL regimen was not well tolerated, with $59 \%$ grade 3-4 diarrhea compared with a rate of $25 \%$ with panitumumab plus FOLFIRI, and had shorter PFS and OS compared with panitumumab combined with FOLFIRI. IFL is currently considered as an inferior schedule compared with FOLFIRI. Köhne et al. also concluded that panitumumab in combination with FOLFIRI represents an effective firstline treatment option for treatment of WT KRAS mCRC [36]. The randomized phase II PEAK trial showed that mFOLFOX6 with panitumumab resulted in longer OS compared with mFOLFOX6 with bevacizumab as first-line treatment in patients with unresectable WT KRAS exon 2
mCRC [37]. A single-arm, phase II trial demonstrated that panitumumab monotherapy may also be a treatment option for the 'frail elderly', who are unable to receive chemotherapy [38]. In 33 patients with a mean age of 81 years who were unfit for chemotherapy, monotherapy with panitumumab resulted in a median PFS of 4.3 months and OS of 7.1 months. There were no grade 4 adverse events or deaths related to panitumumab. The results were confirmed in an observational study with a comparable cohort of 40 'frail elderly' patients with $R A S-B R A F$ WT mCRC [39].

\subsection{Second-Line Therapy}

Table 2 gives an overview of the most substantial evidence for application of panitumumab as part of second-line treatment of mCRC.

Peeters et al. executed a randomized, phase III study of panitumumab with FOLFIRI versus FOLFIRI as secondline therapy for mCRC [40], and all of the 1186 included patients had disease progression during or within 6 months of prior fluoropyrimidine-containing chemotherapy. WT $K R A S$ was not an inclusion criterion but the results presented here are only from the WT KRAS subpopulation (55\% of $91 \%$ of patients with available KRAS status) as there was no effect of the addition of panitumumab on the co-primary endpoints, PFS, and OS in patients with MT KRAS tumors. The ORR was $36 \%$ in the panitumumabFOLFIRI arm compared with $10 \%$ in the FOLFIRI-only arm [41]. The addition of panitumumab significantly improved PFS (6.7 vs. 4.9 months; HR 0.82, 95\% CI $0.69-0.97, p=0.023$ ), and, for OS (14.5 vs. 12.5 months; HR 0.92 , 95\% CI $0.78-1.10, p=0.366)$, a positive trend 
Table 2 Efficacy data of second-line panitumumab trials

\begin{tabular}{|c|c|c|c|c|c|c|c|c|c|}
\hline Study & $\begin{array}{l}K R A S \\
\text { status }\end{array}$ & Treatment arm & $\begin{array}{l}\text { No. of } \\
\text { patients }\end{array}$ & $\begin{array}{l}\text { Median } \\
\text { PFS }\end{array}$ & $\begin{array}{l}\mathrm{HR} \\
(p \text { value })\end{array}$ & Median OS & $\begin{array}{l}\mathrm{HR} \\
(p \text { value })\end{array}$ & $\begin{array}{l}\text { ORR } \\
(\%)\end{array}$ & OR ( $p$ value) \\
\hline \multirow{4}{*}{$\begin{array}{l}\text { Peeters et al. } \\
{[40,41]}\end{array}$} & \multirow[t]{2}{*}{ WT KRAS } & $\mathrm{P}+$ FOLFIRI & 303 & 6.7 months & \multirow{2}{*}{$\begin{array}{l}0.82 \\
\quad(0.023)\end{array}$} & 14.5 months & \multirow{2}{*}{$\begin{array}{l}0.92 \\
\quad(0.366)\end{array}$} & 36.0 & \multirow{2}{*}{$\begin{array}{l}5.50 \\
\quad(<0.0001)\end{array}$} \\
\hline & & FOLFIRI & 294 & 4.9 months & & 12.5 months & & 9.8 & \\
\hline & \multirow[t]{2}{*}{ MT $K R A S$} & $\mathrm{P}+$ FOLFIRI & 238 & 5.3 months & \multirow{2}{*}{$\begin{array}{l}0.94 \\
\quad(0.561)\end{array}$} & 11.8 months & \multirow{2}{*}{$\begin{array}{l}0.93 \\
\quad(0.482)\end{array}$} & 13.4 & \multirow[t]{2}{*}{$0.93(0.89)$} \\
\hline & & FOLFIRI & 248 & 5.4 months & & 11.1 months & & 14.8 & \\
\hline \multirow[t]{2}{*}{ Cohn et al. [42] } & WT $K R A S$ & $\mathrm{P}+$ FOLFIRI & 64 & 26 weeks & \multirow[t]{2}{*}{0.8} & 50 weeks & \multirow[t]{2}{*}{0.6} & 23 & \multirow[t]{2}{*}{1.6} \\
\hline & MT $K R A S$ & $\mathrm{P}+$ FOLFIRI & 45 & 19 weeks & & 31 weeks & & 16 & \\
\hline \multirow[t]{2}{*}{ STEPP $[43,44]$} & WT $K R A S$ & $\begin{array}{l}\mathrm{P}+\text { FOLFIRI or } \\
\text { irinotecan }\end{array}$ & 49 & 5.5 months & \multirow[t]{2}{*}{0.8} & 13.7 months & \multirow[t]{2}{*}{0.8} & 16 & \multirow[t]{7}{*}{2.0} \\
\hline & MT KRAS & $\begin{array}{l}\mathrm{P}+\text { FOLFIRI or } \\
\text { irinotecan }\end{array}$ & 38 & 3.3 months & & 13.1 months & & 8 & \\
\hline \multirow[t]{2}{*}{ SPIRITT [45] } & \multirow[t]{2}{*}{ WT KRAS } & $\mathrm{P}+$ FOLFIRI & 91 & 7.7 months & \multirow[t]{2}{*}{$1.01(0.97)$} & 18.0 months & \multirow[t]{2}{*}{$1.06(0.75)$} & 32 & \\
\hline & & $\mathrm{B}+$ FOLFIRI & 91 & 9.2 months & & 21.4 months & & 19 & \\
\hline \multirow[t]{2}{*}{ Shitara et al. [46] } & \multirow[t]{2}{*}{ WT $K R A S$} & $\mathrm{P}+$ FOLFIRI & 59 & 6.0 months & \multirow[t]{2}{*}{1.14} & 16.2 months & \multirow[t]{2}{*}{1.16} & 46.2 & \\
\hline & & $\mathrm{B}+$ FOLFIRI & 58 & 5.9 months & & 13.4 months & & 5.7 & \\
\hline Carrato et al. [47] & WT $K R A S$ & $\mathrm{P}+$ irinotecan & 53 & 4.5 months & & 15.1 months & & 23 & \\
\hline
\end{tabular}

WT wild-type, $M T$ mutated, $P$ panitumumab, $B$ bevacizumab, FOLFIRI folinic acid/infusional 5-fluorouracil/irinotecan, $P F S$ progression-free survival, $H R$ hazard ratio, $O S$ overall survival, $O R R$ objective response rate, $O R$ odds ratio

was observed. The latter may be the result of crossover after progression in the FOLFIRI arm (34\% of patients). Again, PFS and OS appeared to be longer for subjects with grade 2 or higher skin toxicity compared with patients with grade $0-1$ skin toxicity, or the FOLFIRI-only arm. No premedication was required and very few infusion reactions $(0.7 \%)$ and no fatal reactions were observed. Overall health status and health state index were measured using the EQ-5D scales [31]. Health-related quality of life did not differ between the treatment groups. Baseline scores were relatively high, thus an improvement in quality of life was probably unrealistic.

FOLFIRI with panitumumab in second-line therapy was also examined in phase II trials. The trial by Cohn et al. contributed to the evidence that would later result in the exclusion of people with MT KRAS to receive panitumumab-containing therapy [42]. In the STEPP study, panitumumab was found to be more effective in WT $K R A S$ patients, as well as when administered concomitantly with FOLFIRI or irinotecan as second-line therapy $[43,44]$. In the randomized SPIRITT study, FOLFIRI plus panitumumab had similar PFS and OS compared with FOLFIRI plus bevacizumab for WT KRAS exon 2 patients who were refractory to first-line treatment with chemotherapy containing oxaliplatin and bevacizumab [45]. A recent, randomized, phase II trial by Shitara et al. found comparable results in a study with a similar design [46]. Furthermore, in another phase II trial, panitumumab $(9 \mathrm{mg} / \mathrm{kg})$ administered every 3 weeks together with irinotecan $\left(350 \mathrm{mg} / \mathrm{m}^{2}\right)$ was found to be safe, active, and feasible [47]. In Asian patients, the combination of panitumumab plus irinotecan and S-1 (a combination of tegafur, gimericil and oteracil) showed promising efficacy and an acceptable toxicity profile as second-line therapy for mCRC [48]. S-1 is currently not yet registered in the US or Europe for mCRC.

\subsection{Third and Subsequent Lines of Therapy}

In Table 3, the most prominent outcomes of phase II and III trials, in which panitumumab was studied as a third or further line of treatment, are depicted.

To fully evaluate the effect of panitumumab as monotherapy, a randomized, open-label, phase III trial was performed by Van Cutsem et al. [49]. In this trial, panitumumab plus best supportive care (BSC) was compared with BSC alone, with PFS as the primary endpoint. Patients included had received at least two prior lines of treatment. In the analysis, irrespective of KRAS mutation status, the ORR was $10 \%$ in patients receiving panitumumab and $0 \%$ in patients receiving only BSC. Panitumumab significantly prolonged PFS; median PFS was 8 weeks in this arm versus 7.3 in the BSC arm (HR 0.54, 95\% CI 0.44-0.66, $p<0.0001)$. When only patients with a WT KRAS status were included in the analysis, ORR was $17 \%$ and PFS was 12.3 weeks in the panitumumab arm; the results in the BSC arm were not different from the whole cohort (HR 0.45, 95\% CI $0.34-0.59, p<0.0001)$ [50]. It has to be noted that 
Table 3 Efficacy data of third- and subsequent-line panitumumab trials

\begin{tabular}{|c|c|c|c|c|c|c|c|c|c|}
\hline Study & $\begin{array}{l}K R A S \\
\text { status }\end{array}$ & Treatment arm & $\begin{array}{l}\text { No. of } \\
\text { patients }\end{array}$ & $\begin{array}{l}\text { Median } \\
\text { PFS }\end{array}$ & HR ( $p$ value) & $\begin{array}{l}\text { Median OS } \\
\text { (months) }\end{array}$ & $\begin{array}{l}\text { HR } \\
\text { ( } p \text { value) }\end{array}$ & $\begin{array}{l}\text { ORR } \\
(\%)\end{array}$ & OR ( $p$ value \\
\hline \multirow{4}{*}{$\begin{array}{c}\text { Van Cutsem } \\
{[50,55]}\end{array}$} & \multirow[t]{2}{*}{ WT KRAS } & $\mathrm{P}+\mathrm{BSC}$ & 124 & 12.3 weeks & \multirow{2}{*}{$\begin{array}{l}0.45 \\
\quad(<0.0001)\end{array}$} & 8.1 & \multirow[t]{2}{*}{0.99} & 17 & \\
\hline & & BSC & 119 & 7.3 weeks & & 7.6 & & 0 & \\
\hline & \multirow[t]{2}{*}{ MT $K R A S$} & $\mathrm{P}+\mathrm{BSC}$ & 84 & 7.4 weeks & \multirow[t]{2}{*}{0.99} & 4.9 & \multirow[t]{2}{*}{1.02} & 0 & \\
\hline & & BSC & 100 & 7.3 weeks & & 4.4 & & 0 & \\
\hline \multirow{2}{*}{$\begin{array}{c}\text { ASPECCT } \\
{[56,57]}\end{array}$} & \multirow[t]{2}{*}{ WT $K R A S$} & $\mathrm{P}$ & 499 & 4.2 months & \multirow[t]{2}{*}{0.98} & 10.2 & \multirow[t]{2}{*}{0.94} & 22 & \multirow[t]{2}{*}{1.15} \\
\hline & & $\mathrm{C}$ & 500 & 4.4 months & & 9.9 & & 19.8 & \\
\hline \multirow[t]{2}{*}{ PICCOLO [58] } & \multirow[t]{2}{*}{ WT KRAS } & $\mathrm{P}+$ irinotecan & 230 & & \multirow[t]{2}{*}{$0.78(0.015)$} & 10.4 & \multirow[t]{2}{*}{$1.01(0.91)$} & 34 & \multirow{2}{*}{$\begin{array}{l}4.12 \\
\quad(<0.0001)\end{array}$} \\
\hline & & Irinotecan & 230 & & & 10.9 & & 12 & \\
\hline Hecht et al. [59] & Unselected & $\begin{array}{c}\mathrm{P}(2.5 \mathrm{mg} / \mathrm{kg} \\
\text { weekly })\end{array}$ & 148 & 14 weeks & & 9 & & 9 & \\
\hline Muro et al. [60] & Unselected & $\mathrm{P}$ & 52 & 8.0 weeks & & 9.3 & & 13.5 & \\
\hline Andre et al. [61] & WT $K R A S$ & $\mathrm{P}+$ irinotecan & 65 & 6.3 months & & 11.9 & & 35.2 & \\
\hline
\end{tabular}

$W T$ wild-type, $M T$ mutated, $P$ panitumumab, $C$ cetuximab, $B S C$ best supportive care, $P F S$ progression-free survival, $H R$ hazard ratio, $O S$ overall survival, $O R R$ objective response rate, $O R$ odds ratio

the absolute gain in PFS is fairly small in this group of extensively pretreated patients. OS was not different between treatment groups, probably at least partly because patients in the BSC-alone arm were allowed to enter a crossover study. Patients treated with panitumumab maintained better control over symptoms related to CRC, and reported a better quality of life compared with patients treated with BSC alone, assessed using the FACT Colorectal Cancer Symptom Index and EQ-5D index, respectively [51]. A higher health-related quality of life was associated with absence of disease progression in the panitumumab arm only [52]. Furthermore, longer OS and PFS were correlated with a high grade of skin toxicity (grade 2-4) in patients treated with panitumumab [53]. By combining the efficacy and safety measures in a Q-twist analysis, the quality-adjusted PFS was significantly longer in the panitumumab arm (12.3 weeks) versus the BSCalone arm (5.8 weeks) [54]. In the open-label extension study focusing on safety, 176 of the patients who had progressive disease in the BSC arm received panitumumab monotherapy [55]. Overall, panitumumab was well tolerated; $92 \%$ of patients experienced at least one adverse event related to panitumumab, but grade 3 and 4 adverse events were seen in 16 and $2 \%$ of patients, respectively. Skin toxic effects were most common, and $4 \%$ of the population discontinued therapy because of adverse events.

The ASPECCT study was set up to test if panitumumab was noninferior to cetuximab [56]. This randomized, openlabel, noninferiority, phase III trial compared cetuximab monotherapy with panitumumab monotherapy in patients with WT KRAS exon 2 mCRC. Overall, 999 patients who had disease progression or intolerance to oxaliplatin and irinotecan-based therapy, and had received a thymidylate synthase inhibitor, were treated with one of these drugs in a multinational study in 27 countries. Panitumumab was noninferior to cetuximab with regard to OS, i.e. 10.2 months with panitumumab versus 9.9 months with cetuximab (HR 0.94, 95\% CI 0.82-1.07) [57]. Median PFS was also comparable, i.e. 4.2 and 4.4 months with panitumumab and cetuximab, respectively (HR 0.98, 95\% CI 0.87-1.12). Hypomagnesia and increased skin toxicity appeared to be predictors of longer OS for both EGFR inhibitors. While skin toxicity rates were comparable (13\% with panitumumab, $10 \%$ with cetuximab), the cetuximab arm experienced more infusion reactions ( 12.5 vs. $2.8 \%$ in the panitumumab arm) and the panitumumab arm had a higher incidence of hypomagnesia (7 vs. $3 \%$ in the cetuximab arm).

Panitumumab ( $9 \mathrm{mg} / \mathrm{kg}$ every 3 weeks) plus irinotecan (300-350 mg/m $\mathrm{m}^{2}$ every 3 weeks) was compared with irinotecan alone in the PICCOLO trial [58]. KRAS WT (codons 12, 13, and 61) patients who showed resistance to fluoropyrimidine-containing therapy (at least one prior line of treatment) were selected. These patients did not receive irinotecan or EGFR-targeted therapy prior to commencement of the study. In the primary analysis, 460 patients were included. Patients treated with the combination of irinotecan and panitumumab showed longer PFS (HR 0.78, 95\% CI $0.64-0.95, p=0.015$ ) and a higher ORR (34 and $12 \%$ ), but no difference was seen in OS (HR 1.01, 95\% CI $0.83-1.23, p=0.91$ ) between treatment arms. Skin 
toxicity, grade 3 or higher diarrhea, infection, lethargy, and hematological toxicity were more frequently reported in the combined treatment arm.

The first phase II trial that showed response to panitumumab $(2.5 \mathrm{mg} / \mathrm{kg})$ as monotherapy included patients with $\mathrm{mCRC}$ refractory to therapies with fluoropyrimidine and oxaliplatin or irinotecan, or both [59]. Muro et al. also found panitumumab monotherapy to be effective in Japanese patients who developed progressive disease during or after at least two previous lines of therapy containing irinotecan, oxaliplatin, and fluoropyrimidine [60]. In the study by Andre et al., the combination of panitumumab with irinotecan also appeared active in patients with WT KRAS mCRC refractory to standard chemotherapy [61]. Another single-arm, phase II trial found limited efficacy of irinotecan plus panitumumab as salvage therapy in WT $K R A S$ patients refractory to treatment with irinotecan, oxaliplatin, and fluoropyrimidine [62]. Only 8 of 35 patients showed partial response and six had stable disease. With an ORR of $23 \%$ and a PFS of 2.7 months, response is limited. It has to be noted that 15 patients received a low irinotecan dose $\left(100-120 \mathrm{mg} / \mathrm{m}^{2}\right)$. In patients who received normal doses of irinotecan $\left(150-180 \mathrm{mg} / \mathrm{m}^{2}\right)$, the RR was $30 \%$.

\section{Biomarkers}

Much research dedicated to finding and confirming biomarkers such as RAS, BRAF and EGFR and its ligands to predict the efficacy of panitumumab in certain subpopulations has been performed.

\subsection{RAS}

Ras proteins play an important role in the signal transduction cascade of EGFRs. Depending on whether they are bound to GDP (guanosine diphosphate) or GTP (guanosine triphosphate), they are either in an inactive or active state, respectively. Mutations in RAS (KRAS, NRAS and HRAS) result in a reduction of hydrolysis of ATP bound to Ras, facilitated by GTPase activating proteins (GAPs). Consequently, Ras proteins are in a hyperactive state in patients with mutated $R A S$ [63]. Ras proteins can be activated by other growth factor receptors, therefore when the Ras proteins are in a hyperactive state, blocking the receptor with panitumumab will not result in a significant reduction in signal transduction because Ras proteins will stay active independently of the binding of ligands to EGFR. Single mutations, typically at codons 12,13 , and 61 , can result in an aberrant Ras function.

In the last few years, the indication of panitumumab treatment has been amended to patients with a confirmed
WT RAS tumor status exclusively, where, initially, only WT KRAS was required.

The evidence responsible for limitation of the use of panitumumab to patients with WT KRAS tumors comes from earlier pivotal trials. The extended analysis of the study by Van Cutsem et al. was the first to address this issue. Patients with MT KRAS treated with panitumumab had comparable PFS as those patients treated with BSC (7.4 vs. 7.3 weeks) [50]. Additionally, no responses were observed in the MT KRAS population. The results from the PRIME study and the trial by Peeters et al. confirmed that patients with an MT KRAS status did not benefit from panitumumab treatment. In the PRIME study, FOLFOX4 therapy shows even significantly longer PFS than panitumumab with FOLFOX4 in the MT KRAS population (9.2 vs. 7.4 months; HR $1.27,95 \%$ CI $1.04-1.55, p=0.02$ ). In the trial by Peeters et al., panitumumab combined with FOLFIRI resulted in similar PFS as therapy with FOLFIRI alone in MT KRAS patients (5.3 and 5.4 months; HR 0.94, 95\% CI $0.78-1.14, p=0.561$ ).

Peeters and colleagues retrospectively showed that individual mutations in KRAS codons 12 or 13 have no consistent prognostic or predictive value [64]. They used data from three phase III trials with different treatment regimens containing panitumumab. With this retrospective analysis, it was confirmed that panitumumab should exclusively be used in patients with WT KRAS tumors.

Doi et al. executed an exploratory analysis on data from two studies in Japanese patients to examine whether the association between MT KRAS tumors and worse outcome was similar in this population [65]. In Japanese patients, MT KRAS status was also associated with a lack of response to panitumumab therapy. There was no objective response in 10 patients with MT KRAS tumors, and median PFS was 7.3 weeks, compared with 13.2 weeks in patients with WT KRAS tumors.

The limitations were later extended to WT RAS tumors only, including $K R A S$ exons 2, 3, and 4 and NRAS exons 2, 3 , and 4. The evidence for this requirement to initiate panitumumab therapy is primarily derived from extended analyses of previous described phase II and III trials, especially the PRIME study and the trial by Peeters et al. A summary of the published evidence can be found in Table 4.

The extended RAS analyses of the PRIME trial, the study by Peeters et al. and the trial by Van Cutsem et al. all showed significant longer PFS and OS in the treatment arm that contained panitumumab in WT RAS patients [66-68]. In the MT RAS population, no improvement in survival, or even shorter survival, was seen if panitumumab was combined with FOLFIRI, BSC, or FOLFOX4.

Furthermore, Peeters et al. examined samples from the phase III trial that compared panitumumab plus BSC with 
Table 4 Efficacy data according to $R A S$ and $B R A F$ status in panitumumab trials

\begin{tabular}{|c|c|c|c|c|c|c|c|c|c|}
\hline Study & $\begin{array}{l}R A S / B R A F \\
\text { status }\end{array}$ & Treatment arm & $\begin{array}{l}\text { No. of } \\
\text { patients }\end{array}$ & $\begin{array}{l}\text { Median PFS } \\
\text { (months) }\end{array}$ & $\begin{array}{l}\text { HR } \\
(p \text { value })\end{array}$ & $\begin{array}{l}\text { Median OS } \\
\text { (months) }\end{array}$ & $\begin{array}{l}\mathrm{HR} \\
(p \text { value })\end{array}$ & $\begin{array}{l}\text { ORR } \\
(\%)\end{array}$ & $\begin{array}{l}\text { OR } \\
\text { ( } p \text { value })\end{array}$ \\
\hline \multirow{10}{*}{$\begin{array}{l}\text { PRIME } \\
\qquad[28,66]\end{array}$} & \multirow[t]{2}{*}{ WT $R A S$} & $\mathrm{P}+\mathrm{FOLFOX} 4$ & 259 & 10.1 & \multirow[t]{2}{*}{$0.72(0.04)$} & 25.8 & \multirow{2}{*}{$\begin{array}{l}0.77 \\
\quad(0.009)\end{array}$} & & \\
\hline & & FOLFOX4 & 253 & 7.9 & & 20.2 & & & \\
\hline & \multirow{2}{*}{$\begin{array}{c}\text { WT } K R A S / \mathrm{MT} \\
\text { other } R A S\end{array}$} & $\mathrm{P}+\mathrm{FOLFOX} 4$ & 51 & 7.3 & \multirow[t]{2}{*}{$1.28(0.33)$} & 17.1 & \multirow{2}{*}{$\begin{array}{l}1.39 \\
(0.12)\end{array}$} & & \\
\hline & & FOLFOX4 & 57 & 8.0 & & 17.8 & & & \\
\hline & \multirow[t]{2}{*}{ MT $R A S$} & $\mathrm{P}+\mathrm{FOLFOX} 4$ & 272 & 7.3 & \multirow{2}{*}{$\begin{array}{l}1.31 \\
(0.008)\end{array}$} & 15.5 & \multirow{2}{*}{$\begin{array}{l}1.21 \\
(0.04)\end{array}$} & & \\
\hline & & FOLFOX4 & 276 & 8.7 & & 18.7 & & & \\
\hline & \multirow{2}{*}{$\begin{array}{l}\text { WT } R A S / \mathrm{WT} \\
\text { BRAF }\end{array}$} & $\mathrm{P}+\mathrm{FOLFOX} 4$ & 228 & 10.8 & \multirow{2}{*}{$\begin{array}{l}0.68 \\
\quad(0.002)\end{array}$} & 28.3 & \multirow{2}{*}{$\begin{array}{l}0.74 \\
\quad(0.02)\end{array}$} & & \\
\hline & & FOLFOX4 & 218 & 9.2 & & 20.9 & & & \\
\hline & \multirow{2}{*}{$\begin{array}{l}\text { WT } R A S / \mathrm{MT} \\
\text { BRAF }\end{array}$} & $\mathrm{P}+\mathrm{FOLFOX} 4$ & 24 & 6.1 & \multirow[t]{2}{*}{$0.58(0.12)$} & 10.5 & \multirow{2}{*}{$\begin{array}{l}0.90 \\
\quad(0.76)\end{array}$} & & \\
\hline & & FOLFOX4 & 29 & 5.4 & & 9.2 & & & \\
\hline \multirow{4}{*}{$\begin{array}{c}\text { Köhne et al. } \\
{[36,70]}\end{array}$} & WT $R A S$ & $\mathrm{P}+$ FOLFIRI & 69 & 11.2 & \multirow[t]{2}{*}{0.37} & & & 59 & \multirow[t]{2}{*}{2.0} \\
\hline & MT $R A S$ & $\mathrm{P}+$ FOLFIRI & 74 & 7.3 & & & & 41 & \\
\hline & $\begin{array}{l}\text { WT } R A S / \mathrm{WT} \\
\quad B R A F\end{array}$ & $\mathrm{P}+$ FOLFIRI & 60 & 13.2 & \multirow[t]{2}{*}{0.25} & & & 68 & \multirow[t]{4}{*}{3.7} \\
\hline & $\begin{array}{l}\text { MT } R A S \text { or } \\
\text { MT } B R A F\end{array}$ & $\mathrm{P}+$ FOLFIRI & 83 & 6.9 & & & & 37 & \\
\hline \multirow[t]{2}{*}{ PEAK [37] } & WT $R A S$ & $\mathrm{P}+\mathrm{mFOLFOX6}$ & 88 & 13.0 & \multirow[t]{2}{*}{$\begin{array}{l}0.65 \\
\quad(0.029)\end{array}$} & 41.3 & \multirow[t]{2}{*}{$\begin{array}{l}0.63 \\
(0.058)\end{array}$} & 63.6 & \\
\hline & WT $R A S$ & $\mathrm{~B}+\mathrm{mFOLFOX6}$ & 82 & 9.5 & & 28.9 & & 60.5 & \\
\hline \multirow{10}{*}{$\begin{array}{c}\text { Peeters et al. } \\
{[40,67]}\end{array}$} & \multirow[t]{2}{*}{ WT $R A S$} & $\mathrm{P}+$ FOLFIRI & 208 & 6.4 & 0.70 & 16.2 & 0.81 & 41 & \\
\hline & & FOLFIRI & 213 & 4.6 & $(0.007)$ & 13.9 & $(0.08)$ & 10 & \\
\hline & WT $K R A S / \mathrm{MT}$ & $\mathrm{P}+$ FOLFIRI & 61 & 3.7 & $0.89(0.63)$ & 11.3 & 0.83 & & \\
\hline & other $R A S$ & FOLFIRI & 46 & 3.7 & & 9.2 & $(0.40)$ & & \\
\hline & MT $R A S$ & $\mathrm{P}+$ FOLFIRI & 299 & 4.8 & $0.86(0.14)$ & 11.8 & 0.91 & 15 & \\
\hline & & FOLFIRI & 294 & 4.0 & & 11.1 & $(0.34)$ & 13 & \\
\hline & WT RAS/WT & $\mathrm{P}+$ FOLFIRI & 186 & 6.9 & 0.68 & 18.7 & 0.83 & & \\
\hline & $B R A F$ & FOLFIRI & 190 & 5.5 & $(0.006)$ & 15.4 & $(0.15)$ & & \\
\hline & WT $R A S / \mathrm{MT}$ & $\mathrm{P}+$ FOLFIRI & 22 & 2.5 & $0.69(0.34)$ & 4.7 & 0.64 & & \\
\hline & $B R A F$ & FOLFIRI & 23 & 1.8 & & 5.7 & $(0.20)$ & & \\
\hline Van Cutsem & WT RAS & $\mathrm{P}+\mathrm{BSC}$ & 142 & 5.2 & 0.46 & 10.0 & 0.70 & 31.0 & 20.00 \\
\hline et al. $[55,68]$ & & BSC & 128 & 1.7 & $(<0.0001)$ & 6.9 & $(0.0135)$ & 2.3 & $(<0.0001)$ \\
\hline & WT KRAS/ & $\mathrm{P}+\mathrm{BSC}$ & 26 & 1.6 & 1.03 & 7.6 & 0.99 & 0 & \\
\hline & MT RAS & BSC & 28 & 1.6 & $(0.9429)$ & 7.5 & $(0.9625)$ & 0 & \\
\hline Shitara[46] & $\begin{array}{l}\text { WT } R A S / \mathrm{WT} \\
\quad B R A F\end{array}$ & $\mathrm{P}+$ FOLFIRI & 46 & 18.9 & 1.21 & 7.4 & 1.14 & 52.5 & \\
\hline & $\begin{array}{l}\text { WT } R A S / \mathrm{WT} \\
B R A F\end{array}$ & $\mathrm{~B}+$ FOLFIRI & 44 & 16.1 & & 6.7 & & 2.6 & \\
\hline & $\begin{array}{l}\text { MT } R A S \text { or } \\
\text { MT } B R A F\end{array}$ & $\mathrm{P}+$ FOLFIRI & 8 & 5.4 & 0.42 & 3.2 & 0.54 & 0 & \\
\hline & $\begin{array}{l}\text { MT } R A S \text { or } \\
\text { MT } B R A F\end{array}$ & $\mathrm{~B}+$ FOLFIRI & 11 & 8.2 & & 3.7 & & 18.2 & \\
\hline Andre [61] & $\begin{array}{l}\text { WT } R A S / \mathrm{WT} \\
\quad B R A F\end{array}$ & $\mathrm{P}+$ irinotecan & 41 & 8.7 & & 15.8 & & 46.3 & \\
\hline & $\begin{array}{l}\text { MT } R A S \text { or } \\
\text { MT } B R A F\end{array}$ & $\mathrm{P}+$ irinotecan & 19 & 1.9 & & 4.6 & & 0 & \\
\hline
\end{tabular}

WT wild-type, $M T$ mutated, $P$ panitumumab, FOLFOX folinic acid/infusional 5-fluorouracil/oxaliplatin, FOLFIRI folinic acid/infusional 5-fluorouracil/irinotecan, $B$ bevacizumab, BSC best supportive care, $m F O L F O X$ modified FOLFOX, $P F S$ progression-free survival, $H R$ hazard ratio, $O S$ overall survival, $O R R$ objective response rate, $O R$ odds ratio 
BSC [69]. None of the patients $(n=9)$ with WT KRAS (codons 12, 13, and 61) with an NRAS mutation (codons 12, 13, and 61) responded to panitumumab. The same applies to patients with $B R A F$ mutations $(n=13)$. Patients with WT NRAS (HR 0.39, 95\% CI 0.27-0.56, $p<0.0001$ ) and WT BRAF (HR 0.37, 95\% CI $0.24-0.55, p<0.001$ ) had longer PFS when treated with panitumumab compared with BSC alone, but patients with MT NRAS (HR 1.94, 95\% CI 0.44-8.44, $p=0.379$ ) had a comparable PFS.

In the phase II studies, comparable results were obtained [46, 61, 70]. In the PEAK trial, if $R A S$ mutation status beyond KRAS exon 2 (KRAS exons 2, 3, and 4 plus NRAS exons 2, 3, and 4) was taken into account, the panitumumab arm had better median PFS (13.0 vs. 9.5 months; HR $0.65,95 \%$ CI $0.44-0.96, p=0.029)$ and OS (41.3 vs. 28.9 months; HR $0.63,95 \%$ CI $0.39-1.02, p=0.058)$ than the bevacizumab arm [37].

These findings confirm that chemotherapy combined with panitumumab or panitumumab monotherapy should not be used in patients with MT RAS tumors because there is no survival benefit and an increase in adverse events has been observed. In some reports, the addition of panitumumab has a negative impact on survival parameters in patients with MT RAS tumors; however, in the WT RAS population, there is still a relevant subset of nonresponders. Identification of additional biomarkers is necessary to avoid treatment of patients with anti-EGFR therapy who will not benefit from this treatment, and prevent unnecessary toxicity and costs.

\subsection{BRAF}

$B R A F$ is the gene coding for the protein B-RAF, which plays an important role in the signal transduction pathway of EGFR by regulating MAP kinases and ERK signaling. The predominant $B R A F$ mutation is the $\mathrm{V} 600 \mathrm{E}$ mutation. This $B R A F$ V600E mutation is mutually exclusive with KRAS mutations in CRC [71].

The BRAF MT tumors have been less evaluated than MT RAS tumors. There are fewer randomized trials where $B R A F$ mutation status was recorded and these studies lacked power to show conclusive results. In a meta-analyses, it has been shown that in BRAF-mutated mCRC patients, the addition of an EGFR inhibitor to other therapy does not increase OS, PFS, and ORR [72]. The authors conclude that BRAF MT patients should be excluded from therapy with anti-EGFR antibodies. In another meta-analysis by Rowland and colleagues, $B R A F$ mutation status was not found to be a clear predictive marker for OS and PFS with panitumumab and cetuximab [73]. In that meta-analysis, different statistical methods are used and the inclusion of studies also differs slightly from the meta-analysis by Pietrantonio et al. [72].
Currently, a V600E BRAF mutation is a confirmed worse prognostic marker, and data suggest only a small, nonclinically relevant benefit for anti-EGFR treatment.

\subsection{Epidermal Growth Factor Receptor (EGFR)}

It can be hypothesized that patients with mCRC whose tumors overexpress EGFR respond better to panitumumab treatment. On average, $35 \%$ of patients have an increased gene copy number $(\mathrm{GCN})$ [74]. In 2005, the first association was found between the EGFR GCN and the response to anti-EGFR treatment in CRC [75], and, in subsequent years, more studies followed. In 2013, all data were combined in a meta-analysis because individual studies lacked power. It was shown that median OS (1.61-fold increase) and median PFS (1.54-fold increase) were higher in patients with an increased EGFR GCN when treated with anti-EGFR treatment. Time to progression was unaffected [74]. Data on panitumumab were mainly derived from one study in which patients who did not respond to treatment with irinotecan and oxaliplatin received panitumumab plus BSC or BSC alone [76]. Patients treated with panitumumab $(n=58)$ with a high GCN (defined as tumors with $\geq 43 \%$ chromosome 7 polysomy or mean $\geq 2.47$ EGFR GCN per nucleus) had a higher ORR compared with patients with a low GCN (30-32 vs. 0\%). Longer PFS $(p<0.04)$ and OS $(p<0.02)$ were seen in patients with tumors with $\geq 40 \%$ chromosome 7 polysomy or mean $\geq 2.5$ EGFR GCN per nucleus. For patients treated with $\mathrm{BSC}$ alone $(n=34)$, no correlation was observed between PFS and GCN.

In contrast, Hecht and colleagues found a lack of correlation between EGFR status and response to panitumumab [77]. They combined data on EGFR expression in the tumor from two different phase II studies. Low and high EGFR expression were not associated with an altered ORR, PFS, or OS.

In conclusion, it is not unequivocally proven that a high GCN or high EGFR expression levels are related to a better outcome of panitumumab treatment.

\subsection{EGFR Ligands}

Amphiregulin (AREG) and epiregulin (EREG) are ligands of EGFR. Multiple studies have found indications that the extent of expression of these ligands is related to efficacy of anti-EGFR therapy.

High messenger RNA expression of one of these ligands in WT RAS patients in the PICCOLO trial resulted in longer PFS in the treatment arm with panitumumab (8.3 months) compared with the irinotecan-alone arm (4.4 months), with an HR of $0.38(p<0.001)$, whereas for patients with low expression levels, PFS was comparable 
for both treatment arms [78]. With regard to ORR and OS, results were not significant.

Other studies also showed associations between expression levels of these ligands and survival in patients treated with panitumumab. In one trial, patients with $R A S$ WT tumors with high AREG expression had higher ORR (67 vs. 38\%) compared with tumors with low AREG expression [70].

This association was also found in a smaller trial; high expression levels of EREG (relative to nontumor tissue) and AREG resulted in a higher OS in WT KRAS patients, with HRs of $0.326(p=0.011)$ and $0.277(p=0.019)$, respectively [79]. Furthermore, high ratios of ERBB2, $M E T$, and vascular endothelial growth factor receptor A (VEGFA) between tumor and nontumor tissues were shown to be associated with worse OS.

Similar results were found by Yoshida et al. [80]. AREG, EREG, TGF $\alpha$, and HB-EGFR may be predictive markers for successful treatment with anti-EGFR antibodies. Patients with immunoreactivity to two or more of these ligands had a significantly higher ORR (53.3 vs. $0 \%)$ and longer PFS (231 vs. 79 days) than patients with immunoreactivity to none or one of these ligands.

Several other biomarkers have been the subject of study, including PTEN and PIK3CA, polymorphisms of EGFR, telomere length, circulating tumor cells, tumor budding, microRNA expression, and EGFR downstream phosphoproteins. Moreover, the prognostic and predictive value of clinical biomarkers, such as early tumor shrinkage and depth of response, have recently been explored; however, there is currently insufficient evidence to use these biomarkers in decision making regarding the treatment of patients with panitumumab.

\section{Safety}

In phase I studies, the most prevalent adverse events were discerned and considered acceptable. More robust data on safety issues were derived from phase III studies. The most common adverse reactions were skin reactions, gastrointestinal disorders, fatigue, pyrexia, hypomagnesia and paronychia.

\subsection{Skin Toxicity}

Skin-related toxicity is a direct result of the mechanism of action of panitumumab, as expression of EGFR is high in keratinocytes and hair follicles. Skin reactions are observed in more than $90 \%$ of patients treated with panitumumab, and the US prescribing information contains a boxed warning regarding this cluster of adverse events.
Additional in-depth data on integument-related tolerability were collected in the population of the previously described trial of Köhne et al. Almost all patients (98\% of $154)$ experienced skin-related toxicity, with rash $(42 \%)$, dry skin $(40 \%)$, acne (36\%), and alopecia (34\%) being the most prevalent [81]. Grade 3 or higher toxicities were experienced by $36 \%$ of patients, with rash, acne, and paronychia being the most frequent. The median time to first integument-related toxicity was 8 days, with these toxicities lasting for a median of 334 days. Quality of life was assessed using two validated tools based on patientreported outcomes-the EORTC QLQ-C30 global health status and the EuroQol EQ-5D health state index and overall health. The scores on these scales were comparable at baseline and at the end of follow-up, indicating that skin toxicity did not have a negative impact on quality of life. The ORR was higher in patients who had more severe integument-related toxicity; $56 \%$ in patients with grade 2 or higher skin toxicity versus $29 \%$ with grade $0-1$, indicating that skin toxicity is a predictor of efficacy of panitumumab.

Indeed, the phase III trials made it clear that patients who develop at least grade 2 skin toxicity have better ORR,PFS, and OS. This raises the question whether patients receiving panitumumab with WT RAS status who do not develop skin toxicity should receive a dose escalation to induce skin toxicity or discontinuation of therapy. More research is needed to establish the value of skin toxicity as a prospective biomarker.

Takahashi and colleagues indicated that low serum levels of hepatocyte growth factor, AREG, and EREG prior to the start of treatment with anti-EGFR antibodies might be markers for predicting a high grade of skin toxicity [82]. Additionally, these authors found a higher grade of skin toxicity (grade $2-3$ vs. grade $0-1$ ) correlated with longer PFS and OS.

Other studies investigated whether genetic variation within the EGFR gene could predict EGFR inhibitor-associated skin toxicity [83, 84]. Some polymorphisms and haplotypes have been identified but have not been confirmed in larger RCTs.

Skin toxicity can be prevented by proactive treatment with sunscreen, skin moisturizers, doxycycline, and topical corticosteroids, as was observed in the STEPP trial, which compared pre-emptive skin treatment with reactive treatment [43]. Pre-emptive treatment resulted in meaningful less grade 2 or higher skin toxicity, and patients with this treatment reported better quality of life, assessed using the Dermatology Life Quality Index. The management of EGFR inhibitor-induced skin toxicity was also evaluated in a systemic review [85]. As well as panitumumab, studies on cetuximab and tyrosine kinase inhibitors were included. 
The prophylactic use of systemic tetracyclines was considered the most promising strategy.

\subsection{Gastrointestinal Disorders}

Gastrointestinal disorders seen in patients receiving panitumumab therapy consisted mainly of diarrhea, nausea and vomiting, abdominal pain, and constipation. Diarrhea occurs in approximately $50 \%$ of cases but is most often mild or moderate in severity. Grade 3-4 diarrhea has been reported in approximately $2 \%$ of patients receiving monotherapy, and, in combination with chemotherapy, a rate of approximately $17 \%$ of individuals was observed.

\subsection{Paronychia}

Paronychia has been observed in approximately $20 \%$ of patients treated with panitumumab. It is an inflammation of the fingers and/or toes that involves swelling of the lateral nail folds, and is considered a very cumbersome adverse event.

\subsection{Hypomagnesia}

Hypomagnesia is a common adverse event, occurring in approximately $30 \%$ of patients. Grade 3-4 hypomagnesia has been reported in up to $7 \%$ of treated individuals. Symptoms include seizures, tremor, nystagmus, and cardiac arrest, therefore it is important to monitor magnesium levels of patients treated with panitumumab. Hypomagnesia may be caused by EGFR inhibition in the kidney, leading to magnesium wasting [86]. The higher incidence in patients treated with panitumumab versus cetuximab could be a result of the higher binding affinity to EGFR. It has also been suggested that the occurrence of hypomagnesia during treatment with cetuximab or panitumumab is associated with higher ORR, but data are inconclusive [87].

\subsection{Interstitial Lung Disease}

Interstitial lung disease (ILD) is one of the most serious side effects of panitumumab, with most cases being reported in the Japanese population. The reason for this is unclear, but possible explanations could be genetic susceptibility, different clinical practices or environmental factors, detection bias, and reporting bias. A postmarketing analysis in Japan showed an incidence of ILD of 1.3\% (39 of 3085 patients), with a high mortality rate of $51.3 \%$ (20 of 39 cases) [88]. The following risk factors for ILD were identified: male sex, older than 65 years of age, a history of ILD, poor general condition, and no history of previous drug treatment for CRC (including cetuximab). Interstitial pneumonitis or pulmonary fibrosis are contraindications for the use of panitumumab. In patients with a history of these conditions, the benefits of therapy versus the risk of pulmonary complications should be carefully considered.

\subsection{Infusion Reactions}

Infusion-related reactions were reported in only $4 \%$ of patients treated with panitumumab, of whom $<1 \%$ were grade 3 or higher. No premedication was required prior to administration of panitumumab [12].

\section{Discussion and Conclusions}

The anti-EGFR antibody panitumumab has now been available for more than 10 years for the treatment of RAS WT mCRC. The PK have been well-established, with a dual clearance mechanism, via binding to the EGFR and via the reticuloendothelial system. The mechanism of action depends largely on the blockade of EGFR, thereby preventing the binding of endogenous ligands and its effects on tumor growth, survival, and metastasis. The immunogenicity of panitumumab is very low, a consequence of panitumumab being a fully human antibody. Panitumumab is registered and used in all lines of therapy for the treatment of mCRC, in combination with chemotherapy and as monotherapy. Until now, the only (retrospectively) confirmed predictive biomarker is $R A S$, but others are expected, particularly with regard to $B R A F$. Anti-EGFR therapy in patients with an RAS-mutated mCRC is detrimental for outcome. In terms of safety, the high incidence of skin toxicity is especially notable, which predicts a better response compared with no skin toxicity. Overall, panitumumab is well tolerated.

Despite its mature state of clinical development, some topics of debate, recent discoveries, and future developments regarding panitumumab are to be considered, including its place relative to cetuximab and bevacizumab in the treatment of mCRC, the potential combination therapy of panitumumab and bevacizumab, and the most effective chemotherapy backbone to combine with panitumumab. These, among other matters, will be discussed below.

The place of panitumumab relative to another available anti-EGFR antibody, cetuximab, is still unclear. Only the ASPECCT trial reported data on the prospective head-tohead comparison of panitumumab and cetuximab in a randomized clinical trial, and showed that both drugs had similar efficacy [56, 57]; however, both drugs appeared to have a different safety profile. A higher incidence of hypersensitivity reactions and infusion reactions was seen with cetuximab, probably due to the fact that cetuximab is 
a chimeric antibody, whereas panitumumab is a fully human antibody. Alternatively, hypersensitivity reactions may be caused by galactose- $\alpha-1,3$-galactose, a component added during the manufacturing process of cetuximab for post-translational modification, or by residues of murinederived $\mathrm{N}$-glycolylneuraminic acid, which is introduced during the manufacturing process $[89,90]$. In contrast, panitumumab showed more cases of severe hypomagnesia $[56,57]$.

In a meta-analysis, it was shown that both drugs were related to a significantly increased risk of grade 3-4 infections, but only cetuximab was associated with a higher incidence of febrile neutropenia [91]. In this analysis, studies where anti-EGFR mAbs were used for indications other than mCRC, were also included. When the comorbidity and medical history of individual patients are taken into account, these differences in adverse events could result in the preference of one drug over the other on an individual patient level.

The earlier-discussed higher potential of cetuximab in triggering ADCC compared with panitumumab does not result in increased efficacy. Panitumumab may compensate for the lesser activation of ADCC with its higher binding affinity to EGFR, or the effects of ADCC may play an insignificant role compared with the receptor-blocking action.

Treating patients with panitumumab after they received prior cetuximab is only indicated when treatment with cetuximab is discontinued for reasons other than disease progression, e.g. hypersensitivity reactions [92-96].

The place of panitumumab relative to the angiogenesis inhibitor bevacizumab, an antibody directed against VEGFA, is another point of debate. As previously discussed, three studies investigated panitumumab versus bevacizumab $[37,45,46]$. The randomized, phase II PEAK trial found an advantage of panitumumab treatment on PFS and OS in a subpopulation of patients with WT RAS tumors [37]. In WT KRAS patients, only OS was significantly improved with panitumumab plus mFOLFOX6 compared with bevacizumab plus mFOLFOX6. In the phase II SPIRITT study, a higher ORR was seen in favor of patients treated with panitumumab plus FOLFIRI versus bevacizumab plus FOLFIRI [45]. PFS and OS were comparable in both treatment arms. The trial conducted by Shitara et al. also showed a trend toward improved OS in patients who were WT RAS and BRAF in the FOLFIRI plus panitumumab arm compared with the FOLFIRI plus bevacizumab arm [46].

In cases of cetuximab versus bevacizumab, the results are also variable. The FIRE-3 study compared cetuximab plus FOLFIRI with bevacizumab plus FOLFIRI as first-line therapy of mCRC in a randomized, open-label, phase III trial [97]. Although ORR (primary endpoint) and PFS were similar for both regimens in WT KRAS patients, the combination with cetuximab showed a significantly longer OS (28.7 vs. 25.0 months). In the RAS WT population, the median depth of response and frequency of early tumor shrinkage, obtained by centralized radiological review, were significantly better in the cetuximab arm [98]. In contrast, the not yet published CALGB study found no differences in survival outcomes between cetuximab versus bevacizumab, both in combination with chemotherapy as first-line treatment [99].

Based on the available evidence, panitumumab or bevacizumab cannot be preferred over the other as first- or second-line therapy in mCRC. More data are warranted to have a better selection of patients for anti-EGFR versus anti-VEGF treatment. Extended analysis of biomarkers might be an important tool in selecting patients who benefit most from panitumumab treatment.

It has recently been shown that patients with a tumor located on the right side do not benefit from anti-EGFR therapy. Brulé et al. found that patients with right-sided colon cancer did not benefit from cetuximab therapy compared with BSC (median PFS 1.9 and 1.9 months, respectively), while patients with left-sided colon cancer did benefit (median PFS 5.4 and 1.8 months, respectively) [3]. In a retrospective analysis of the FIRE-3 and CRYSTAL studies in the RAS WT population, patients with right-sided tumors had markedly inferior ORR, PFS, and OS compared with patients with left-sided tumors [4]. The efficacy benefits relative to the comparative therapy are much higher in patients with left-sided tumors compared with patients with right-sided tumors. A recent metaanalysis including the PRIME and PEAK trials confirms that the addition of an anti-EGFR agent to chemotherapy in first-line therapy only results in survival benefit in patients with WT RAS left-sided tumors but not in right-sided WT $R A S$ tumors [5]. Additionally, anti-EGFR therapy results in significantly longer survival in the WT RAS population with left-sided tumors compared with bevacizumab. These findings will affect prescription guidelines and label claims at short notice.

The PACCE trial was the first study where panitumumab and bevacizumab were combined as treatment for mCRC; however, this combination failed as a treatment option in the first line. A similar study was performed with cetuximab. In the CAIRO2 trial, cetuximab was combined with oxaliplatin, capecitabine, and bevacizumab as firstline therapy, and then compared with the same regimen without cetuximab [100]. The addition of cetuximab resulted in a significantly shorter PFS (primary endpoint) and inferior quality of life. OS and RR were not significantly different for both treatment groups, while patients in the treatment arm with cetuximab experienced more grade 3-4 adverse events. A recently published retrospective 
cohort study by Taniguchi et al. showed that a short interval ( $<6$ months) between bevacizumab and anti-EGFR antibody treatment may interfere with the efficacy of the subsequent anti-EGFR therapy [101]. Although only 14 of 114 patients (WT KRAS exon 2) received panitumumab plus irinotecan, others received cetuximab with irinotecan. A higher RR and longer PFS and OS were seen if the interval between bevacizumab and anti-EGFR antibody therapy was at least 6 months compared with a shorter interval. However, the combination of bevacizumab and panitumumab is still the subject of research.

A recent phase I study showed that panitumumab $6 \mathrm{mg} /$ $\mathrm{kg}$ every 2 weeks is the recommended dose in combination with bevacizumab $5 \mathrm{mg} / \mathrm{kg}$ every 2 weeks [102]; no doselimiting toxicities were seen in three Japanese patients receiving this regimen. Liu and colleagues provide the most recently published evidence. In this randomized, phase II trial, FOLFIRI was compared with FOLFIRI plus panitumumab (4 mg/kg biweekly) and bevacizumab (4 mg/kg biweekly) as second-line treatment [103]. Independent of KRAS mutation status, this combination was able to prolong PFS, OS, and RR compared with FOLFIRI alone, at the cost of additional grade 3-4 adverse events, but these were tolerable. This second-line therapy was first evaluated in other phase II trials using lower doses of both drugs $[104,105]$. The mechanisms of potential antagonistic effects of combined VEGF and anti-EGFR antibodies are still unclear. Acquired resistance to bevacizumab might be associated with co-resistance to anti-EGFR therapy, or a PD interaction between the two might be responsible. Another possibility is the inclusion of oxaliplatin in the chemotherapy backbone. In the PACCE trial, this was mainly the case, as well as in the CAIRO2 study, which is in contrast with more recent research where irinotecan is used. More data are warranted to get a final answer on the feasibility and efficacy of this combination-targeted therapy.

Regarding the chemotherapy backbone, panitumumab can be combined with FOLFOX and FOLFIRI; however, the addition of FOLFOX has only been investigated as first-line therapy, whereas FOLFIRI is not included in the US label. On the other hand, the US label of cetuximab only states the combination with irinotecan-containing regimens. As no large studies have been performed with the aim of comparing the different chemotherapy backbones directly, no definite conclusions can be drawn to what the most optimal chemotherapy regimen is to combine with anti-EGFR treatment. As described in the previous paragraph, the combination of bevacizumab and panitumumab or cetuximab only seems to prolong survival in combination with irinotecan-containing chemotherapy schedules. The COIN trial showed that there is a lack of benefit in the addition of cetuximab to oxaliplatin-based chemotherapy in first-line treatment of WT KRAS mCRC [106], although it is unclear if these findings are the result of the inclusion of oxaliplatin in the chemotherapy backbone or of the use of CAPOX, which was the most common chemotherapy regimen in this study. Further study on the most optimal chemotherapy to combine with antiEGFR treatment is required.

For the last few years, the use of panitumumab has been limited to RAS WT mCRC only. However, even in this population, there is still a substantial subgroup of patients who have no objective response when treated with panitumumab. Other biomarkers may be able to predict a lack of efficacy. V600E BRAF mutation status seems to be important, although its predictive role has not been unequivocally established until now. There is little evidence on the best treatment of patients with MT BRAF tumors. A pilot trial explored whether treatment with vemurafenib combined with panitumumab for patients with MT BRAF tumors is suitable [98]. Treatment was well tolerated, but showed only modest clinical activity in this subset of chemoresistant and highly aggressive mCRC.

EGFR GCN, EGFR expression, levels of EGFR ligands, and other potential biomarkers should be examined in this newly defined population of patients with RAS WT tumors, and a predictive role might become apparent. The purpose of these studies would be to better define the population that profits from panitumumab therapy and to further reduce the number of patients who are unnecessarily treated with panitumumab, resulting in adverse events in the absence of an objective response.

Overall, this review shows that panitumumab is a valuable therapy in the treatment of left-sided mCRC in all lines of therapy, with RAS WT as a predictive biomarker. More research is needed to better define the subpopulation that will benefit most from treatment with panitumumab. The place of panitumumab in treatment, compared with other drugs, especially bevacizumab and cetuximab, should also be further investigated.

\section{Compliance with Ethical Standards}

Funding No sources of funding were used to assist in the preparation of this review.

Conflict of interest Sander Ketzer, Kirsten J.M. Schimmel, Miriam Koopman, and Henk-Jan Guchelaar declare that they have no conflicts of interest.

Open Access This article is distributed under the terms of the Creative Commons Attribution-NonCommercial 4.0 International License (http://creativecommons.org/licenses/by-nc/4.0/), which permits any noncommercial use, distribution, and reproduction in any medium, provided you give appropriate credit to the original author(s) and the source, provide a link to the Creative Commons license, and indicate if changes were made. 


\section{References}

1. Siegel RL, Miller KD, Jemal A. Cancer statistics, 2016. CA Cancer J Clin. 2016;66(1):7-30.

2. Torre LA, Bray F, Siegel RL, Ferlay J, Lortet-Tieulent J, Jemal A. Global cancer statistics, 2012. CA Cancer J Clin. 2015;65(2):87-108.

3. Brulé SY, Jonker DJ, Karapetis CS, O'Callaghan CJ, Moore MJ, Wong R, et al. Location of colon cancer (right-sided versus leftsided) as a prognostic factor and a predictor of benefit from cetuximab in NCIC CO.17. Eur J Cancer. 2015;51(11):1405-14.

4. Tejpar S, Stintzing S, Ciardiello F, Tabernero J, Van Cutsem E, Beier $\mathrm{F}$ et al. Prognostic and predictive relevance of primary tumor location in patients with RAS wild-type metastatic colorectal cancer: retrospective analyses of the CRYSTAL and FIRE-3 trials. JAMA Oncol. doi:10.1001/jamaoncol.2016.3797. [Epub 10 Oct 2016].

5. Holch JW, Ricard I, Stintzing S, Modest DP, Heinemann V. The relevance of primary tumour location in patients with metastatic colorectal cancer: a meta-analysis of first-line clinical trials. Eur J Cancer. 2017;70:87-98.

6. Yewale C, Baradia D, Vhora I, Patil S, Misra A. Epidermal growth factor receptor targeting in cancer: a review of trends and strategies. Biomaterials. 2013;34(34):8690-707.

7. Modjtahedi H, Essapen S. Epidermal growth factor receptor inhibitors in cancer treatment: advances, challenges and opportunities. Anticancer Drugs. 2009;20(10):851-5.

8. Ciardiello F, Tortora G. EGFR antagonists in cancer treatment. N Engl J Med. 2008;358(11):1160-74.

9. Perkins G, Lievre A, Ramacci C, Meatchi T, de Reynies A, Emile JF, et al. Additional value of EGFR downstream signaling phosphoprotein expression to KRAS status for response to antiEGFR antibodies in colorectal cancer. Int $\mathrm{J}$ Cancer. 2010;127(6):1321-31.

10. Vecitibix: EPAR. http://www.ema.europa.eu/docs/en_GB/ document_library/EPAR_-_Product_Information/human/ 000741/WC500047710.pdf. Accessed 25 Oct 2016.

11. Vectibix prescribing information. Thousend Oaks, CA; Amgen Inc. Accessed 23 Dec 2016. http://pi.amgen.com/ /media/ amgen/repositorysites/pi-amgen-com/vectibix/vectibix_pi.ashx.

12. Weiner LM, Belldegrun AS, Crawford J, Tolcher AW, Lockbaum P, Arends RH, et al. Dose and schedule study of panitumumab monotherapy in patients with advanced solid malignancies. Clin Cancer Res. 2008;14(2):502-8.

13. Doi T, Ohtsu A, Tahara M, Tamura T, Shirao K, Yamada Y, et al. Safety and pharmacokinetics of panitumumab in Japanese patients with advanced solid tumors. Int $\mathrm{J}$ Clin Oncol. 2009; 14(4):307-14

14. Stephenson JJ, Gregory C, Burris H, Larson T, Verma U, Cohn A, et al. An open-label clinical trial evaluating safety and pharmacokinetics of two dosing schedules of panitumumab in patients with solid tumors. Clin Colorectal Cancer. 2009;8(1):29-37.

15. Rowinsky EK, Schwartz GH, Gollob JA, Thompson JA, Vogelzang NJ, Figlin R, et al. Safety, pharmacokinetics, and activity of ABX-EGF, a fully human anti-epidermal growth factor receptor monoclonal antibody in patients with metastatic renal cell cancer. J Clin Oncol. 2004;22(15):3003-15.

16. Foon KA, Yang XD, Weiner LM, Belldegrun AS, Figlin RA, Crawford J, et al. Preclinical and clinical evaluations of ABXEGF, a fully human anti-epidermal growth factor receptor antibody. Int J Radiat Oncol Biol Phys. 2004;58(3):984-90.

17. Ma P, Yang BB, Wang YM, Peterson M, Narayanan A, Sutjandra L, et al. Population pharmacokinetic analysis of panitumumab in patients with advanced solid tumors. J Clin Pharmacol. 2009;49(10):1142-56.
18. Dirks NL, Nolting A, Kovar A, Meibohm B. Population pharmacokinetics of cetuximab in patients with squamous cell carcinoma of the head and neck. J Clin Pharmacol. 2008;48(3):267-78.

19. Yang BB, Wu CY, Chen E, Infante JR, Chen A, Gao B, et al. Pharmacokinetics of irinotecan with and without panitumumab coadministration in patients with metastatic colorectal cancer. Clin Pharmacol Drug Dev. 2013;2(3):205-12.

20. Yang XD, Jia XC, Corvalan JR, Wang P, Davis CG, Jakobovits A. Eradication of established tumors by a fully human monoclonal antibody to the epidermal growth factor receptor without concomitant chemotherapy. Cancer Res. 1999;59(6):1236-43.

21. Goldstein NI, Prewett M, Zuklys K, Rockwell P, Mendelsohn J. Biological efficacy of a chimeric antibody to the epidermal growth factor receptor in a human tumor xenograft model. Clin Cancer Res. 1995;1(11):1311-8.

22. Naramura M, Gillies SD, Mendelsohn J, Reisfeld RA, Mueller BM. Therapeutic potential of chimeric and murine anti-(epidermal growth factor receptor) antibodies in a metastasis model for human melanoma. Cancer Immunol Immunother. 1993;37(5):343-9.

23. Alvarenga ML, Kikhney J, Hannewald J, Metzger AU, Steffens $\mathrm{KJ}$, Bomke J, et al. In-depth biophysical analysis of interactions between therapeutic antibodies and the extracellular domain of the epidermal growth factor receptor. Anal Biochem. 2012;421(1):138-51.

24. Lopez-Albaitero A, Ferris RL. Immune activation by epidermal growth factor receptor specific monoclonal antibody therapy for head and neck cancer. Arch Otolaryngol Head Neck Surg. 2007;133(12):1277-81.

25. Schneider-Merck T, Lammerts van Bueren JJ, Berger S, Rossen K, van Berkel PH, Derer $S$, et al. Human $\mathrm{IgG} 2$ antibodies against epidermal growth factor receptor effectively trigger antibody-dependent cellular cytotoxicity but, in contrast to $\mathrm{IgG} 1$, only by cells of myeloid lineage. J Immunol. 2010;184(1):512-20.

26. Lofgren JA, Dhandapani S, Pennucci JJ, Abbott CM, Mytych DT, Kaliyaperumal A, et al. Comparing ELISA and surface plasmon resonance for assessing clinical immunogenicity of panitumumab. J Immunol. 2007;178(11):7467-72.

27. Weeraratne D, Chen A, Pennucci JJ, Wu CY, Zhang K, Wright $\mathrm{J}$, et al. Immunogenicity of panitumumab in combination chemotherapy clinical trials. BMC Clin Pharmacol. 2011;11:17.

28. Douillard JY, Siena S, Cassidy J, Tabernero J, Burkes R, Barugel M, et al. Randomized, phase III trial of panitumumab with infusional fluorouracil, leucovorin, and oxaliplatin (FOLFOX4) versus FOLFOX4 alone as first-line treatment in patients with previously untreated metastatic colorectal cancer: the PRIME study. J Clin Oncol. 2010;28(31):4697-705.

29. Douillard JY, Siena S, Cassidy J, Tabernero J, Burkes R, Barugel M, et al. Final results from PRIME: randomized phase III study of panitumumab with FOLFOX4 for first-line treatment of metastatic colorectal cancer. Ann Oncol. 2014;25(7):1346-55.

30. Siena S, Tabernero J, Bodoky G, Cunningham D, Rivera F, Ruff $\mathrm{P}$, et al. Quality of life during first-line FOLFOX $4+/-$ panitumumab in RAS wild-type metastatic colorectal carcinoma: results from a randomised controlled trial. ESMO Open. 2016;1(2):e000041.

31. Bennett L, Zhao Z, Barber B, Zhou X, Peeters M, Zhang J, et al. Health-related quality of life in patients with metastatic colorectal cancer treated with panitumumab in first-or second-line treatment. Br J Cancer. 2011;105(10):1495-502.

32. Wang J, Hechmati G, Dong J, Maglinte GA, Barber B, Douillard JY. Q-TWiST analysis of panitumumab plus FOLFOX4 versus FOLFOX4 alone in patients with previously untreated wild-type RAS metastatic colorectal cancer. Curr Med Res Opin. 2016;32(3):459-65. 
33. Hecht JR, Mitchell E, Chidiac T, Scroggin C, Hagenstad C, Spigel D, et al. A randomized phase IIIB trial of chemotherapy, bevacizumab, and panitumumab compared with chemotherapy and bevacizumab alone for metastatic colorectal cancer. J Clin Oncol. 2009;27(5):672-80.

34. Giusti RM, Cohen MH, Keegan P, Pazdur R. FDA review of a panitumumab (Vectibix) clinical trial for first-line treatment of metastatic colorectal cancer. Oncologist. 2009;14(3):284-90.

35. Berlin J, Posey J, Tchekmedyian S, Hu E, Chan D, Malik I, et al. Panitumumab with irinotecan/leucovorin/5-fluorouracil for firstline treatment of metastatic colorectal cancer. Clin Colorectal Cancer. 2007;6(6):427-32.

36. Köhne CH, Hofheinz R, Mineur L, Letocha H, Greil R, Thaler J, et al. First-line panitumumab plus irinotecan/5-fluorouracil/leucovorin treatment in patients with metastatic colorectal cancer. J Cancer Res Clin Oncol. 2012;138(1):65-72.

37. Schwartzberg LS, Rivera F, Karthaus M, Fasola G, Canon JL, Hecht JR, et al. PEAK: a randomized, multicenter phase II study of panitumumab plus modified fluorouracil, leucovorin, and oxaliplatin (mFOLFOX6) or bevacizumab plus mFOLFOX6 in patients with previously untreated, unresectable, wild-type KRAS exon 2 metastatic colorectal cancer. J Clin Oncol. 2014;32(21):2240-7.

38. Sastre J, Massuti B, Pulido G, Guillen-Ponce C, Benavides M, Manzano JL, et al. First-line single-agent panitumumab in frail elderly patients with wild-type KRAS metastatic colorectal cancer and poor prognostic factors: a phase II study of the Spanish Cooperative Group for the Treatment of Digestive Tumours. Eur J Cancer. 2015;51(11):1371-80.

39. Pietrantonio F, Cremolini C, Aprile G, Lonardi S, Orlandi A, Mennitto A, et al. Single-agent panitumumab in frail elderly patients with advanced RAS and BRAF wild-type colorectal cancer: challenging drug label to light up new hope. Oncologist. 2015;20(11):1261-5.

40. Peeters M, Price TJ, Cervantes A, Sobrero AF, Ducreux M, Hotko Y, et al. Randomized phase III study of panitumumab with fluorouracil, leucovorin, and irinotecan (FOLFIRI) compared with FOLFIRI alone as second-line treatment in patients with metastatic colorectal cancer. J Clin Oncol. 2010;28(31):4706-13.

41. Peeters M, Price TJ, Cervantes A, Sobrero AF, Ducreux M, Hotko Y, et al. Final results from a randomized phase 3 study of FOLFIRI + $/$ - panitumumab for second-line treatment of metastatic colorectal cancer. Ann Oncol. 2014;25(1):107-16.

42. Cohn AL, Shumaker GC, Khandelwal P, Smith DA, Neubauer MA, Mehta N, et al. An open-label, single-arm, phase 2 trial of panitumumab plus FOLFIRI as second-line therapy in patients with metastatic colorectal cancer. Clin Colorectal Cancer. 2011;10(3):171-7.

43. Lacouture ME, Mitchell EP, Piperdi B, Pillai MV, Shearer H, Iannotti N, et al. Skin toxicity evaluation protocol with panitumumab (STEPP), a phase II, open-label, randomized trial evaluating the impact of a pre-emptive skin treatment regimen on skin toxicities and quality of life in patients with metastatic colorectal cancer. J Clin Oncol. 2010;28(8):1351-7.

44. Mitchell EP, Piperdi B, Lacouture ME, Shearer H, Iannotti N, Pillai MV, et al. The efficacy and safety of panitumumab administered concomitantly with FOLFIRI or Irinotecan in second-line therapy for metastatic colorectal cancer: the secondary analysis from STEPP (Skin Toxicity Evaluation Protocol With Panitumumab) by KRAS status. Clin Colorectal Cancer. 2011;10(4):333-9.

45. Hecht JR, Cohn A, Dakhil S, Saleh M, Piperdi B, Cline-Burkhardt M, et al. SPIRITT: a randomized, multicenter, phase II study of panitumumab with FOLFIRI and bevacizumab with FOLFIRI as second-line treatment in patients with unresectable wild type KRAS metastatic colorectal cancer. Clin Colorectal Cancer. 2015;14(2):72-80.

46. Shitara K, Yonesaka K, Denda T, Yamazaki K, Moriwaki T, Tsuda $\mathrm{M}$, et al. A randomized study of FOLFIRI plus either panitumumab or bevacizumab for wild-type KRAS colorectal cancer-WJOG 6210G. Cancer Sci. 2016;107(12):1843-50.

47. Carrato A, Gomez A, Escudero P, Chaves M, Rivera F, Marcuello E, et al. Panitumumab and irinotecan every 3 weeks is an active and convenient regimen for second-line treatment of patients with wild-type K-RAS metastatic colorectal cancer. Clin Transl Oncol. 2013;15(9):705-11.

48. Takaoka T, Kimura T, Shimoyama R, Kawamoto S, Sakamoto $\mathrm{K}$, Goda F, et al. Panitumumab in combination with irinotecan plus S-1 (IRIS) as second-line therapy for metastatic colorectal cancer. Cancer Chemother Pharmacol. 2016;78(2):397-403.

49. Van Cutsem E, Peeters M, Siena S, Humblet Y, Hendlisz A, Neyns B, et al. Open-label phase III trial of panitumumab plus best supportive care compared with best supportive care alone in patients with chemotherapy-refractory metastatic colorectal cancer. J Clin Oncol. 2007;25(13):1658-64.

50. Amado RG, Wolf M, Peeters M, Van CE, Siena S, Freeman DJ, et al. Wild-type KRAS is required for panitumumab efficacy in patients with metastatic colorectal cancer. J Clin Oncol. 2008;26(10):1626-34.

51. Odom D, Barber B, Bennett L, Peeters M, Zhao Z, Kaye J, et al. Health-related quality of life and colorectal cancer-specific symptoms in patients with chemotherapy-refractory metastatic disease treated with panitumumab. Int $\mathbf{J}$ Colorectal Dis. 2011;26(2):173-81.

52. Siena S, Peeters M, Van CE, Humblet Y, Conte P, Bajetta E, et al. Association of progression-free survival with patient-reported outcomes and survival: results from a randomised phase 3 trial of panitumumab. Br J Cancer. 2007;97(11):1469-74.

53. Peeters M, Siena S, Van CE, Sobrero A, Hendlisz A, Cascinu S, et al. Association of progression-free survival, overall survival, and patient-reported outcomes by skin toxicity and KRAS status in patients receiving panitumumab monotherapy. Cancer. 2009;115(7):1544-54.

54. Wang J, Zhao Z, Barber B, Sherrill B, Peeters M, Wiezorek J. A Q-TWiST analysis comparing panitumumab plus best supportive care (BSC) with BSC alone in patients with wild-type KRAS metastatic colorectal cancer. $\mathrm{Br} \mathrm{J}$ Cancer. 2011;104(12):1848-53.

55. Van Cutsem E, Siena S, Humblet Y, Canon JL, Maurel J, Bajetta E, et al. An open-label, single-arm study assessing safety and efficacy of panitumumab in patients with metastatic colorectal cancer refractory to standard chemotherapy. Ann Oncol. 2008;19(1):92-8.

56. Price TJ, Peeters M, Kim TW, Li J, Cascinu S, Ruff P, et al. Panitumumab versus cetuximab in patients with chemotherapyrefractory wild-type KRAS exon 2 metastatic colorectal cancer (ASPECCT): a randomised, multicentre, open-label, non-inferiority phase 3 study. Lancet Oncol. 2014;15(6):569-79.

57. Price T, Kim TW, Li J, Cascinu S, Ruff P, Suresh AS, et al. Final results and outcomes by prior bevacizumab exposure, skin toxicity, and hypomagnesaemia from ASPECCT: randomized phase 3 non-inferiority study of panitumumab versus cetuximab in chemorefractory wild-type KRAS exon 2 metastatic colorectal cancer. Eur J Cancer. 2016;68:51-9.

58. Seymour MT, Brown SR, Middleton G, Maughan T, Richman S, Gwyther S, et al. Panitumumab and irinotecan versus irinotecan alone for patients with KRAS wild-type, fluorouracil-resistant advanced colorectal cancer (PICCOLO): a prospectively stratified randomised trial. Lancet Oncol. 2013;14(8):749-59.

59. Hecht JR, Patnaik A, Berlin J, Venook A, Malik I, Tchekmedyian S, et al. Panitumumab monotherapy in patients with 
previously treated metastatic colorectal cancer. Cancer. 2007;110(5):980-8.

60. Muro K, Yoshino T, Doi T, Shirao K, Takiuchi H, Hamamoto Y, et al. A phase 2 clinical trial of panitumumab monotherapy in Japanese patients with metastatic colorectal cancer. Jpn J Clin Oncol. 2009;39(5):321-6.

61. Andre T, Blons H, Mabro M, Chibaudel B, Bachet JB, Tournigand C, et al. Panitumumab combined with irinotecan for patients with KRAS wild-type metastatic colorectal cancer refractory to standard chemotherapy: a GERCOR efficacy, tolerance, and translational molecular study. Ann Oncol. 2013;24(2):412-9.

62. Nishi T, Hamamoto Y, Nagase M, Denda T, Yamaguchi K, Amagai K, et al. Phase II trial of panitumumab with irinotecan as salvage therapy for patients with advanced or recurrent colorectal cancer (TOPIC study). Oncol Lett. 2016;11(6):4049-54.

63. Schubbert S, Shannon K, Bollag G. Hyperactive Ras in developmental disorders and cancer. Nat Rev Cancer. 2007;7(4):295-308.

64. Peeters M, Douillard JY, Van CE, Siena S, Zhang K, Williams $\mathrm{R}$, et al. Mutant KRAS codon 12 and 13 alleles in patients with metastatic colorectal cancer: assessment as prognostic and predictive biomarkers of response to panitumumab. J Clin Oncol. 2013;31(6):759-65.

65. Doi T, Tahara M, Yoshino T, Yamazaki K, Tamura T, Yamada $\mathrm{Y}$, et al. Tumor KRAS status predicts responsiveness to panitumumab in Japanese patients with metastatic colorectal cancer. Jpn J Clin Oncol. 2011;41(2):210-6.

66. Douillard JY, Oliner KS, Siena S, Tabernero J, Burkes R, Barugel $\mathrm{M}$, et al. Panitumumab-FOLFOX4 treatment and RAS mutations in colorectal cancer. $\mathrm{N}$ Engl $\mathrm{J}$ Med. 2013;369(11):1023-34.

67. Peeters M, Oliner KS, Price TJ, Cervantes A, Sobrero AF, Ducreux $M$, et al. Analysis of KRAS/NRAS mutations in a phase III study of panitumumab with FOLFIRI compared with FOLFIRI alone as second-line treatment for metastatic colorectal cancer. Clin Cancer Res. 2015;21(24):5469-79.

68. Kim TW, Elme A, Kusic Z, Park JO, Udrea AA, Kim SY, et al. A phase 3 trial evaluating panitumumab plus best supportive care vs best supportive care in chemorefractory wild-type KRAS or RAS metastatic colorectal cancer. $\mathrm{Br} \mathrm{J}$ Cancer. 2016;115(10):1206-14.

69. Peeters M, Oliner KS, Parker A, Siena S, Van CE, Huang J, et al. Massively parallel tumor multigene sequencing to evaluate response to panitumumab in a randomized phase III study of metastatic colorectal cancer. Clin Cancer Res. 2013;19(7):1902-12.

70. Karthaus M, Hofheinz RD, Mineur L, Letocha H, Greil R, Thaler J, et al. Impact of tumour RAS/BRAF status in a first-line study of panitumumab + FOLFIRI in patients with metastatic colorectal cancer. Br J Cancer. 2016;115(10):1215-22.

71. Sartore-Bianchi A, Di Nicolantonio F, Nichelatti M, Molinari F, De Dosso S, Saletti P, et al. Multi-determinants analysis of molecular alterations for predicting clinical benefit to EGFRtargeted monoclonal antibodies in colorectal cancer. PLoS One. 2009;4(10):e7287.

72. Pietrantonio F, Petrelli F, Coinu A, Di Bartolomeo M, Borgonovo K, Maggi C, et al. Predictive role of BRAF mutations in patients with advanced colorectal cancer receiving cetuximab and panitumumab: a meta-analysis. Eur J Cancer. 2015;51(5):587-94.

73. Rowland A, Dias MM, Wiese MD, Kichenadasse G, McKinnon RA, Karapetis CS, et al. Meta-analysis of BRAF mutation as a predictive biomarker of benefit from anti-EGFR monoclonal antibody therapy for RAS wild-type metastatic colorectal cancer. Br J Cancer. 2015;112(12):1888-94.
74. Jiang Z, Li C, Li F, Wang X. EGFR gene copy number as a prognostic marker in colorectal cancer patients treated with cetuximab or panitumumab: a systematic review and meta analysis. PLoS One. 2013;8(2):e56205.

75. Moroni M, Veronese S, Benvenuti S, Marrapese G, SartoreBianchi A, Di Nicolantonio F, et al. Gene copy number for epidermal growth factor receptor (EGFR) and clinical response to antiEGFR treatment in colorectal cancer: a cohort study. Lancet Oncol. 2005;6(5):279-86.

76. Sartore-Bianchi A, Moroni M, Veronese S, Carnaghi C, Bajetta E, Luppi G, et al. Epidermal growth factor receptor gene copy number and clinical outcome of metastatic colorectal cancer treated with panitumumab. J Clin Oncol. 2007;25(22):3238-45.

77. Hecht JR, Mitchell E, Neubauer MA, Burris HA III, Swanson P, Lopez $\mathrm{T}$, et al. Lack of correlation between epidermal growth factor receptor status and response to panitumumab monotherapy in metastatic colorectal cancer. Clin Cancer Res. 2010;16(7):2205-13.

78. Seligmann JF, Elliott F, Richman SD, Jacobs B, Hemmings G, Brown $\mathrm{S}$ et al. Combined epiregulin and amphiregulin expression levels as a predictive biomarker for panitumumab therapy benefit or lack of benefit in patients with RAS wild-type advanced colorectal cancer. JAMA Oncol. doi:10.1001/ jamaoncol.2015.6065. [Epub 11 Feb 2016].

79. Takahashi N, Iwasa S, Taniguchi H, Sasaki Y, Shoji H, Honma $Y$, et al. Prognostic role of ERBB2, MET and VEGFA expression in metastatic colorectal cancer patients treated with antiEGFR antibodies. Br J Cancer. 2016;114(9):1003-11.

80. Yoshida M, Shimura T, Sato M, Ebi M, Nakazawa T, Takeyama $\mathrm{H}$, et al. A novel predictive strategy by immunohistochemical analysis of four EGFR ligands in metastatic colorectal cancer treated with anti-EGFR antibodies. J Cancer Res Clin Oncol. 2013;139(3):367-78.

81. Thaler J, Karthaus M, Mineur L, Greil R, Letocha H, Hofheinz $\mathrm{R}$, et al. Skin toxicity and quality of life in patients with metastatic colorectal cancer during first-line panitumumab plus FOLFIRI treatment in a single-arm phase II study. BMC Cancer. 2012;12:438.

82. Takahashi N, Yamada Y, Furuta K, Nagashima K, Kubo A, Sasaki Y, et al. Association between serum ligands and the skin toxicity of anti-epidermal growth factor receptor antibody in metastatic colorectal cancer. Cancer Sci. 2015;106(5):604-10.

83. Parmar S, Schumann C, Rudiger S, Boeck S, Heinemann V, Kachele V, et al. Pharmacogenetic predictors for EGFR-inhibitor-associated skin toxicity. Pharmacogenomics J. 2013;13(2):181-8.

84. Saito R, Suzuki H, Yamada T, Endo S, Moriwaki T, Ueno T, et al. Predicting skin toxicity according to EGFR polymorphisms in patients with colorectal cancer receiving antibody against EGFR. Anticancer Res. 2013;33(11):4995-8.

85. Baas JM, Krens LL, Guchelaar HJ, Ouwerkerk J, de Jong FA, Lavrijsen AP, et al. Recommendations on management of EGFR inhibitor-induced skin toxicity: a systematic review. Cancer Treat Rev. 2012;38(5):505-14.

86. Maliakal P, Ledford A. Electrolyte and protein imbalance following anti-EGFR therapy in cancer patients: a comparative study. Exp Ther Med. 2010;1(2):307-11.

87. Fujii H, Iihara H, Suzuki A, Kobayashi R, Matsuhashi N, Takahashi T, et al. Hypomagnesemia is a reliable predictor for efficacy of anti-EGFR monoclonal antibody used in combination with first-line chemotherapy for metastatic colorectal cancer. Cancer Chemother Pharmacol. 2016;77(6):1209-15.

88. Osawa M, Kudoh S, Sakai F, Endo M, Hamaguchi T, Ogino Y, et al. Clinical features and risk factors of panitumumab-induced interstitial lung disease: a postmarketing all-case surveillance study. Int J Clin Oncol. 2015;20(6):1063-71. 
89. Chung CH, Mirakhur B, Chan E, Le QT, Berlin J, Morse M, et al. Cetuximab-induced anaphylaxis and $\operatorname{IgE}$ specific for galactose-alpha-1,3-galactose. N Engl J Med. 2008;358(11): 1109-17.

90. Ghaderi D, Taylor RE, Padler-Karavani V, Diaz S, Varki A. Implications of the presence of $N$-glycolylneuraminic acid in recombinant therapeutic glycoproteins. Nat Biotechnol. 2010;28(8):863-7.

91. Funakoshi T, Suzuki M, Tamura K. Infectious complications in cancer patients treated with anti-EGFR monoclonal antibodies cetuximab and panitumumab: a systematic review and metaanalysis. Cancer Treat Rev. 2014;40(10):1221-9.

92. Lau SC, Chung V, Lim D, Shibata S. Panitumumab following disease progression on cetuximab in patients with metastatic colorectal cancer: a retrospective review. J Oncol Pharm Pract. 2014;20(2):83-7.

93. Pietrantonio F, Perrone F, Biondani P, Maggi C, Lampis A, Bertan C, et al. Single agent panitumumab in KRAS wild-type metastatic colorectal cancer patients following cetuximab-based regimens: clinical outcome and biomarkers of efficacy. Cancer Biol Ther. 2013;14(12):1098-103.

94. Saif MW, Kaley K, Chu E, Copur MS. Safety and efficacy of panitumumab therapy after progression with cetuximab: experience at two institutions. Clin Colorectal Cancer. 2010;9(5):315-8.

95. Sonoda H, Mekata E, Shimizu T, Endo Y, Tani T. Safety and efficacy of panitumumab therapy after metastatic colorectal cancer progression with cetuximab: experience at a single Japanese institution. Oncol Lett. 2013;5(4):1331-4.

96. Wadlow RC, Hezel AF, Abrams TA, Blaszkowsky LS, Fuchs $\mathrm{CS}$, Kulke MH, et al. Panitumumab in patients with KRAS wildtype colorectal cancer after progression on cetuximab. Oncologist. 2012;17(1):14.

97. Heinemann V, von Weikersthal LF, Decker T, Kiani A, Vehling-Kaiser U, Al-Batran SE, et al. FOLFIRI plus cetuximab versus FOLFIRI plus bevacizumab as first-line treatment for patients with metastatic colorectal cancer (FIRE-3): a randomised, open-label, phase 3 trial. Lancet Oncol. 2014;15(10): 1065-75.

98. Stintzing S, Modest DP, Rossius L, Lerch MM, von Weikersthal LF, Decker T, et al. FOLFIRI plus cetuximab versus FOLFIRI plus bevacizumab for metastatic colorectal cancer (FIRE-3): a post-hoc analysis of tumour dynamics in the final RAS wild-type subgroup of this randomised open-label phase 3 trial. Lancet Oncol. 2016;17(10):1426-34.

99. Venook A, Niedzwiecki D, Lenz HJ, Innocenti F, Mahoney MR, O'Neil B, et al. Calgb/swog 80405: phase III trial of irinotecan/ 5-fu/leucovorin (FOLFIRI) or oxaliplatin/5-fu/ leucovorin (mFOLFOX6) with bevacizumab (BV) or cetuximab (CET) for patients (Pts) with KRAS wild-type (WT) untreated metastatic adenocarcinoma of the colon. Ann Oncol. 2014;25:ii112-3.

100. Tol J, Koopman M, Cats A, Rodenburg CJ, Creemers GJ, Schrama JG, et al. Chemotherapy, bevacizumab, and cetuximab in metastatic colorectal cancer. $N$ Engl $J$ Med. 2009;360(6):563-72.

101. Taniguchi H, Komori A, Narita Y, Kadowaki S, Ura T, Andoh $\mathrm{M}$, et al. A short interval between bevacizumab and anti-epithelial growth factor receptor therapy interferes with efficacy of subsequent anti-EGFR therapy for refractory colorectal cancer. Jpn J Clin Oncol. 2016;46(3):228-33.

102. Takahashi N, Iwasa S, Fukahori M, Sudo K, Sasaki Y, Shoji H, et al. A phase I study of the combination of panitumumab and bevacizumab in KRAS wild-type colorectal cancer patients previously treated with fluoropyrimidine, oxaliplatin, irinotecan and bevacizumab. Cancer Chemother Pharmacol. 2016;78(3):567-75.

103. Liu Y, Luan L, Wang X. A randomized phase II clinical study of combining panitumumab and bevacizumab, plus irinotecan, 5-fluorouracil, and leucovorin (FOLFIRI) compared with FOLFIRI alone as second-line treatment for patients with metastatic colorectal cancer and KRAS mutation. Onco Targets Ther. 2015;8:1061-8.

104. Xie S, Han G, Fan Z, He L, Xu W, Qin Z. Safety and efficacy of second-line treatment with folinic acid, 5-fluorouracil and irinotecan (FOLFIRI) in combination of panitumumab and bevacizumab for patients with metastatic colorectal cancer. Med Oncol. 2014;31(7):35.

105. Liang HL, Hu AP, Li SL, Liu JY. Combining bevacizumab and panitumumab with irinotecan, 5-fluorouracil, and leucovorin (FOLFIRI) as second-line treatment in patients with metastatic colorectal cancer. Med Oncol. 2014;31(6):976.

106. Maughan TS, Adams RA, Smith CG, Meade AM, Seymour MT, Wilson RH, et al. Addition of cetuximab to oxaliplatin-based first-line combination chemotherapy for treatment of advanced colorectal cancer: results of the randomised phase 3 MRC COIN trial. Lancet. 2011;377(9783):2103-14. 